\title{
Theoretical Perspectives and Therapeutic Approaches in Music Therapy with Families:
}

\section{An International Survey Study}

\author{
Kirsi Tuomi ${ }^{1 *}$, Grace Thompson ${ }^{2}$, Tali Gottfried ${ }^{3}$, Esa Ala-Ruona ${ }^{4}$ \\ 1 Department of Music, Art and Culture Studies, University of Jyväskylä, Finland \\ 2 Faculty of Fine Arts and Music, University of Melbourne, Australia \\ 3 Graduate Program for Special Education, Herzog Academic College, Israel \\ 4 Department of Music, Art and Culture Studies, University of Jyväskylä, Finland \\ *Kirsi.tuomi@myllytalo.fi
}

Received: 16 January 2020 Accepted: 26 May 2021 Published: 1 July 2021

Editor: Marisol Norris Reviewers: Jasmine Edwards, Scott Horowitz

\begin{abstract}
Music therapists have described the importance of working collaboratively with family members in various populations throughout the history of the profession. Despite the growing amount of literature, not enough is known regarding the scope of theoretical perspectives and therapeutic approaches that guide family centered music therapy. The aim of this international survey study was to better understand the professional perspectives and approaches of music therapists who work with families around the world. This article presents the results of the survey where a total of 125 responses were analysed. Participants' responses indicated that music therapy with families is well established as an important field of practice that includes a large range of populations across the life span. Music therapists working with families emphasise that the work is holistic and flexible, both in terms of the theoretical approaches that inform their work and the methods/techniques that are included in sessions. The participants in this study advocated for more continuing professional development opportunities to further deepen and develop their practice. In addition, the survey data offers priorities and recommendations for future research.
\end{abstract}

Keywords: music therapy, family work, families, survey

\section{Background}

Music therapists have acknowledged the importance of working with the whole family throughout the history of the profession. Pioneers such as Juliette Alvin (1978), who worked with children with disabilities and autism, ${ }^{1}$ described the value of guiding parents to use music therapy strategies in the home and community. Since then, music therapy practitioners and researchers have continued to document and describe their work with families. The 1990s were a time where seminal research that included fam- 
ily perspectives, including case studies and theoretical frameworks, were published around the world (Hibben, 1992; Muller \& Warwick, 1993; Oldfield, 1993; Shoemark, 1996; Trondalen, 1997). The growing amount of literature published over the past 10 years (Tuomi et al., 2017) indicates that 'music therapy with families' may now be considered a field of its own, influenced by ecological understanding (Williams et al., 2014), and the shifting descriptions of theoretical influences (Lindahl-Jacobsen \& Thompson, 2017b). In light of this tendency, the Music Therapy with Families Network was founded at the 2011 Nordic Music Therapy Conference in Jyväskylä, where the first family centered symposium was presented (Thompson, 2017). Since then, the Network has continued to grow, and to date has attracted over 400 international members who are part of a professional social media group. The Network members collaborate regularly to present at international music therapy conferences.

Music therapy is, broadly speaking, a relational and contextual practice (Helle-Valle et al., 2017; Rolvsjord \& Stige, 2015). Family centered practice in music therapy has been described as an ecological approach where the primary focus is on promoting health within and between family members (Bruscia, 1998). An ecological systems approach is a developmental viewpoint where the environmental conditions necessary for the development of human beings are considered and emphasised (Brofenbrenner, 1979, 1981; Crooke, 2015). From this viewpoint, the notion of "client" includes the whole family-the therapist may work to facilitate changes in one family member which will ultimately lead to changes in the whole family system and vice versa (Bruscia, 1998).

The first three authors have been working together in the Music Therapy with Families Network since 2011. They each have extensive clinical experience working with families in music therapy, have all conducted research in the field, and also have teaching and training experience. The fourth author has extensive experience in clinical work, consultation, training and research within various fields of music therapy. The authors come from Scandinavian, Middle Eastern and Australasian countries, which brought together a diverse range of perspectives to the research.

\section{Literature Review}

Many music therapists describe the importance of working collaboratively with family members in various populations, demonstrating the vast breadth of work that can be considered part of this field. Populations where there have been several publications include: neonates (i.e., Gooding \& Trainor, 2018; Ettenberger et al., 2017; Haslbeck, 2012; Haslbeck et al., 2018; Loewy, 2015; Shoemark et al., 2015; Teckenberg-Jansson et al., 2011) autistic children (i.e., Blauth, 2016; Gottfried, 2016; Gottfried et al., 2018; Thompson, 2012; Thompson et al., 2014; Walworth, 2012), disabled children (i.e., Loth, 2008; Oldfield, 2008; Williams et al., 2012), hospitalized children and adults (i.e., Ayson, 2008; Baron, 2017; O'Callaghan \& Jordan, 2011; Shoemark, 2004; Shoemark \& Dearn, 2008), survivors of trauma (i.e., Colegrove et al., 2018; Drake, 2011; Hasler, 2008; Salkeld, 2008; Stuart, 2018; Tuomi, 2017), survivors of child abuse (i.e., Jacobsen \& McKinney, 2015; Oldfield, 2017), people with life limiting conditions (i.e., Aasgaard, 2001; Lindenfelser et al., 2008; Lindenfelser et al., 2012; Savage \& Taylor Johnston, 2013), refugees (i.e., Edwards et al., 2007; Oscarsson, 2017), and people with dementia (i.e., Beer, 2017; Raglio et al., 2016; Ridder, 2017).

While the number of publications focused on music therapy with families has steadly increased (Tuomi et al., 2017), little is known about the professional practice of qualified music therapists. Various workforce surveys have been conducted around the world that provide some insight into the professional profile of therapists working with families. For example, a national survey study in the United States of America $(n=$ 328) documented the ways music therapists work with people on the autism spectrum (Kern et al., 2013). In Finland, approaches to early childhood music therapy was documented ( $n=25$; Tuomi \& Ala-Ruona, 2011, 2013) and parent-infant music therapy was surveyed in the Netherlands $(n=106$, from which 25 people identified as working 
with families; Krantz, 2014). In the United Kingdom, a survey explored music therapy practice in children's hospices and attitudes towards the service $(n=22$; Hodkinson et al., 2014). Most recently, music therapists working in neonatal intensive care unit in the USA participated a survey exploring the focus and approach of clinical work, as well as training factors ( $n=54$; Gooding \& Trainor, 2018).

Looking across the results from these different studies indicated that collaboration in various forms was an important aspect of music therapy practice with families. For example, in the study from the USA, 78\% of music therapists working with autistic people collaborated with family members or other caregivers (Kern et al., 2013). In the Netherlands, the most common practice was to include parents directly within the sessions (Krantz, 2014), and this tendency was also reported from children's hospice settings in the UK (Hodkinson et al., 2014).

Other common approaches to music therapy practice with families include consultation with family members and professionals or separate conselling sessions for different family members. In Finland, counselling sessions for parents are reported to be the most common way of approaching family centered practice (Tuomi \& Ala-Ruona, 2013). In USA, 79.3\% of music therapists working with people with autism spectrum include consultative services to families or other professionals (Kern et al., 2013). In addition, informal support for parents is provided by music therapists before and after sessions in children's hospice settings (Hodkinson et al., 2014).

In previous surveys of paediatric settings, music therapists indicated that they address the needs of parents in the NICU environment (Gooding \& Trainor, 2018) and children's hospice environment (Hodkinson et al., 2014). However, only the first mentioned survey documented the music therapy methods and techniques most commonly used in music therapy, such as infant-directed singing, parent counseling, psychoeducation, music-assisted relaxation, musical recordings and information about how to use music at home (Gooding \& Trainor, 2018).

More recently, a large survey study collected descriptive data about practice status, clinical trends and training needs of 2,495 music therapists from around the world (Kern \& Tague 2017). Although this study did not include direct information concerning family centered practice per se, it is the only international study of this magnitude from the field of music therapy. The study findings revealed that communication, emotional support, and social skills were the predominant aims of music therapy sessions. Singing/vocalization, instrument play, and musical improvisation were the most frequently used music therapy techniques. Music therapists most commonly reported working with people with conditions such as autism (44.2\%), developmental disabilities (32.4\%) and depression (31\%).

These surveys offer some insight into the working practices of qualified music therapists. However, in relation to working with families, the data is fragmented, local and in many cases concentrated on a specific client population. Additional information is therefore needed to better represent the breadth of theoretical perspectives and therapeutic approaches that guide music therapists who work with families around the world. Furthermore, not enough is known about the music therapy methods used in collaborative relationships with the family members during the sessions.

\section{Aim of the Study}

The aim of the study was to better understand the professional perspectives and approaches of music therapists who work with families around the world. In particular, the survey questions aim to map the main theoretical perspectives, therapeutic approaches, and practical considerations of this professional community. Not only will this information potentially help to plan future professional education/training and supervision, it will also provide a snapshot of the profession in order to track changes in the relevance of different therapeutic frameworks utilized by music therapists working with families. 


\section{Method}

\section{Design}

The survey method was selected to hopefully capture a comprehensive international view of the professional perspectives and approaches of music therapists working with families. The survey questions were developed by the authors through a series of steps with the intention that responses could be completed anonymously by participants via an online platform. The first step involved a series of research meetings. The authors identified key issues (Smith et al., 2016) and discussed differences in terminology according to their own international perspectives and cultural contexts. Through these discussions, diverse definitions and experiences of educational and theoretical frameworks, clinical populations, and music therapy methods were explored. The multiplechoice questions were designed to be easy and quick to answer. Since there was no budget for translation to multiple lanugages, the questions needed to be clear and concrete, and written in accessible English language expression for a professional and multi-lingual audience who are experienced with accessing literature, training seminars and conference presentations in English (Smith et al., 2016).

The second step involved a pilot of the questions. Since the survey was targeted to professional music therapists who define themselves as working in a family-centered way, the authors approached several colleagues from an online support group Music Therapy with Families Network and asked them to complete the questions and provide feedback. The group consists of professional music therapists working with families, many of whom are also experienced researchers in the field, and whose first language is not necessarily English. Altogether, nine evaluations of the pilot questions were received between March and April 2018. The authors then worked to refine the questions into their final format taking into account the feedback provided. The final version of the survey consisted of 22 questions (see Table 1 ).

The third and final step involved the roll-out of the online survey via Webropol. The survey was open from 13.9.2018 until 7.1.2019. An invitation to participate in the survey was published in several closed Facebook groups ${ }^{2}$ including the Music Therapy with Families Network (275 members), Music Therapy in Child Welfare (128 memembers), Music Therapists Unite! (5901 members), School Based Music Therapists (335 members), Music Therapists Working in Mental Health (953 members), and Music Therapy and Hospice \& Palliative Care (1112 members). In addition, national Facebook pages for professional music therapy associations were invited to post an invitation, including China, India, Latin America, Spain, Australia, Israel and Finland. E-mail invitations to participate were circulated to members by the World Federation for Music Therapy, European Music Therapy Confederation, and British Association for Music Therapy. All announcements and invitations were posted up to three times. Individuals were also encouraged to forward the invitation to other colleagues. Despite the high numbers of people in each professional group, it is likely that the same people were members of multiple networks/groups. Therefore, it is not possible to estimate the final invited sample size.

At the beginning of the survey, the respondents were asked to authorize that their data can be used by the research team for the purposes of the study. The study follows the ethical codes of the University of Jyväskylä, Finland. While the online platform did not collect names and contact information, any survey responses in the open comments were checked and deidentified prior to analysis. The survey questions are provided in Table 1.

\section{Participants and Data}

A total of 134 people responded to the survey. Of these, nine people indicated that they were not trained music therapists, and were therefore removed from the analysis. The final number of complete responses was 125 . 
Table 1

Survey questions

\begin{tabular}{|c|c|}
\hline $\begin{array}{l}\text { Question } \\
\text { Number }\end{array}$ & Question \\
\hline 1 & I confirm that I am a qualified music therapist. \\
\hline 2 & $\begin{array}{l}\text { I am willing to participate in this international survey of music therapy with families, and un- } \\
\text { derstand the purpose of the survey is for research. }\end{array}$ \\
\hline 3 & $\begin{array}{l}\text { I authorize the team of the researchers ( } x x x x x x x x x x x x) \text { to use the survey data for the research } \\
\text { purposes according to the etchical guidelines of the University of Jyväskylä, Finland, which in- } \\
\text { cludes preserving the anonymity of the participants and secure storage of data. }\end{array}$ \\
\hline 4 & What is your gender? \\
\hline 5 & What is your age? \\
\hline 6 & What is your highest level of education in music therapy? \\
\hline 7 & In which country did you complete your first qualification in music therapy? \\
\hline 8 & In what year did you start working as a music therapist? \\
\hline 9 & In which country are you currently practicing music therapy? \\
\hline 10 & In what year did you start working with family members in your music therapy practice? \\
\hline 11 & With which clinical population do you work with families in music therapy? * \\
\hline 12 & When working with families in music therapy, where do sessions take place? * \\
\hline 13 & Please describe your theoretical framework when working with families * \\
\hline 14 & $\begin{array}{l}\text { What music therapy methods do you use when working with families in music therapy ses- } \\
\text { sions? * }\end{array}$ \\
\hline 15 & $\begin{array}{l}\text { What non-music based therapy techniques do you use when working with families in music } \\
\text { therapy sessions? * }\end{array}$ \\
\hline 16 & $\begin{array}{l}\text { There are various models for working with families in music therapy. Which of the following } \\
\text { models best describe your work? * }\end{array}$ \\
\hline 17 & $\begin{array}{l}\text { If the family members are present in music therapy sessions, who typically attends with the } \\
\text { child/adult client? }\end{array}$ \\
\hline 18 & $\begin{array}{l}\text { If family members participate in separate / additional counselling sessions, how frequently } \\
\text { do these sessions occur? * }\end{array}$ \\
\hline 19 & $\begin{array}{l}\text { If family members participate in counceling sessions, which techniques / methods do you } \\
\text { use with them? * }\end{array}$ \\
\hline 20 & In general, how would you describe your role as a music therapist working with families? \\
\hline 21 & $\begin{array}{l}\text { To your knowledge, do any specialist music therapy training courses in working with families } \\
\text { exist in your country? }\end{array}$ \\
\hline 22 & $\begin{array}{l}\text { What would you like to see included in music therapy training programs and updating educa- } \\
\text { tion to help students and music therapy clinicians develop their skills in working with fami- } \\
\text { lies? Please describe. }\end{array}$ \\
\hline
\end{tabular}

*Note: These questions included "other" as part of the multiple choice answers, and respondents could provide more information as free text.

Of the 22 questions, 19 were multiple choice and three allowed a free open-text answer. The respondents were asked to answer every question, with several multiple choice questions including an "other" option that also allowed for further explanation via an open-text field (see Table 1). The complete survey is provided in Appendix 1. 
Table 2

Age of respondents

\begin{tabular}{|l|l|l|}
\hline \multicolumn{1}{|c|}{ Age } & \multicolumn{1}{|c|}{$n$} & \multicolumn{1}{c|}{ Percent } \\
\hline $20-29$ & 21 & $16.80 \%$ \\
\hline $30-39$ & 43 & $24.40 \%$ \\
\hline $40-49$ & 27 & $21.60 \%$ \\
\hline $50-59$ & 20 & $16 \%$ \\
\hline $60-69$ & 14 & $11.20 \%$ \\
\hline over 70 & 0 & $0 \%$ \\
\hline
\end{tabular}

\section{Analysis}

The first step when analysing the data was to examine the "other - please describe" free-text answers to the multiple-choice questions. The first author read through the free text and determined if the answer could be incorporated into the existing categories. If it could not, a new category was proposed and discussed by all authors. In this case also those entries mentioned only once were categorised as their own, aiming to present the picture of the data as authentic as possible. The meaning of some answers were unclear, provided feedback on the survey question, or more conversational in nature and were excluded.

Next, the three open-ended questions which invited a free-text response underwent a qualitative content analysis (QCA). Using the guiding question "What is intended to be said?" (Bengtson, 2016; Bruscia, 2016), the first author worked to systematically analyse and classify the text into an organised and concise summary of key categories (Bruscia, 2016; Erlingsson \& Brysiewicz, 2017). The systematic coding was carried out in an inductive way in order to identify meaningful themes that addressed the research questions (Bengtsson, 2016). The first round of coding was broad and aimed to stay faithful to the original text and expressions of the participant. Next, the codes were categorized by grouping related codes together, and discussed amongst all authors. Finally, the frequency of comments related to each category was descriptively analysed.

\section{Results}

\section{Demographic Data}

The respondents were mostly female (90\%) and aged between 30-39-years-old. There were no participants over 70 years of age (Table 2).

Most respondents stated their highest qualification in music therapy to be Masters (44\%), followed by Bachelors (21\%) and Doctoral (18\%). Only $2 \%$ of respondents indicated that they had a pre-Bachelor (sometimes called 'clinical training') qualification. Further, 19 respondents had aquired additional music therapy training, including GIM (Guided Imagery and Music Bonny Method; $n=4$ ), NICU (Neonatal Intensive Care Unit music therapy; $n=3$ ), NMT (Neurologic Music Therapy; $n=3$ ) and APCI (Assessment of Parent-Child Interaction; $n=1$ ).

Geographically, most respondents reported that their first qualification was undertaken in Europe $(n=54)$ and North America $(n=43)$, followed by Oceania $(n=16)$, Asia $(n=9)$ and Latin America $(n=3)$. There were no respondents from Africa. In response to the question "In which country are you currently practicing music therapy?" there was no significant difference compared to the respondents' country of qualification (Figure 1).

The highest number of respondents reported to have begun working as a music therapist within last 7 years $(44 \%, n=55)$, while $28 \%$ of the participants had been working for over 18 years $(n=49)$. Further, $72 \%(n=91)$ of the respondents reported that they began working with families within 2006-2018. However, according to this 


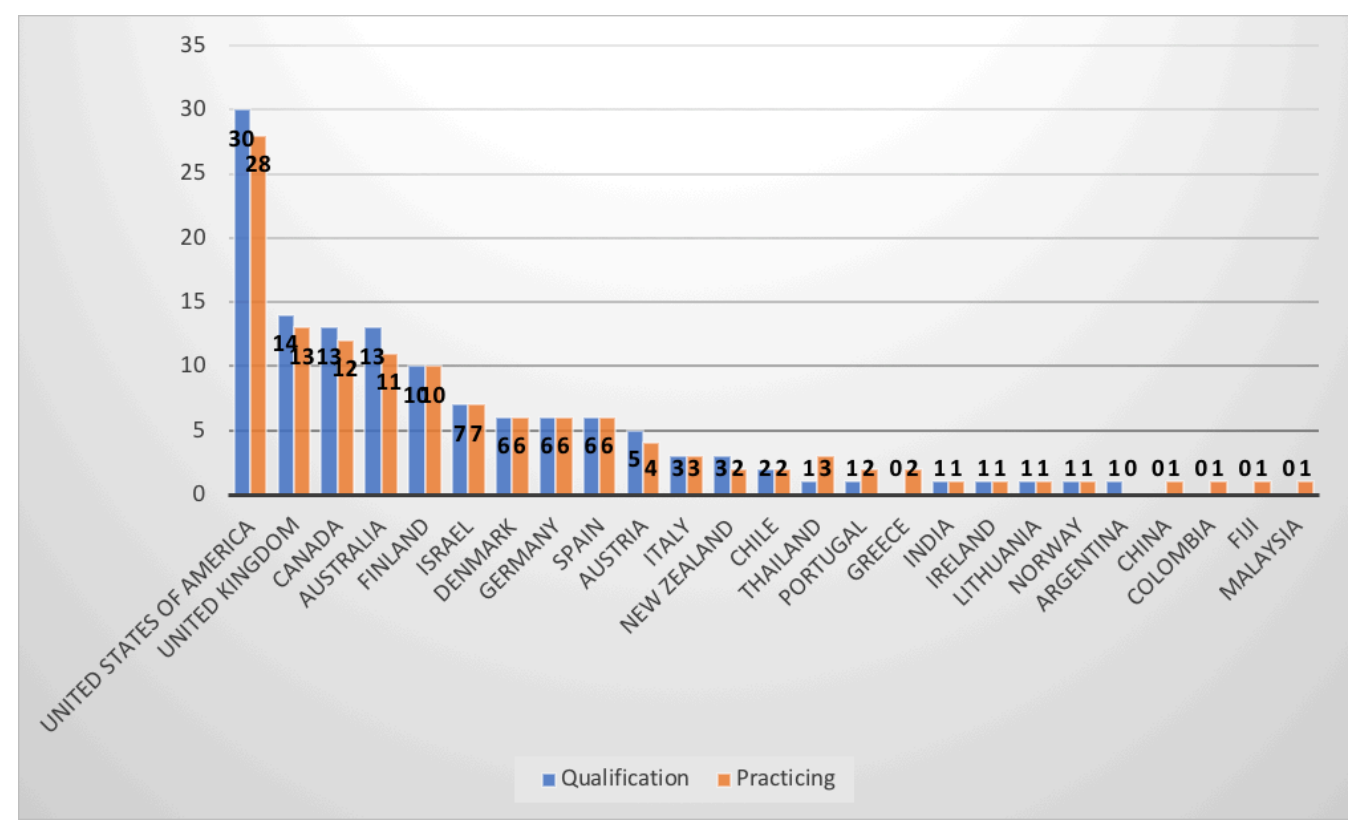

Figure 1

Geographical diversity of respondents' country of qualification and current country practicing music therapy

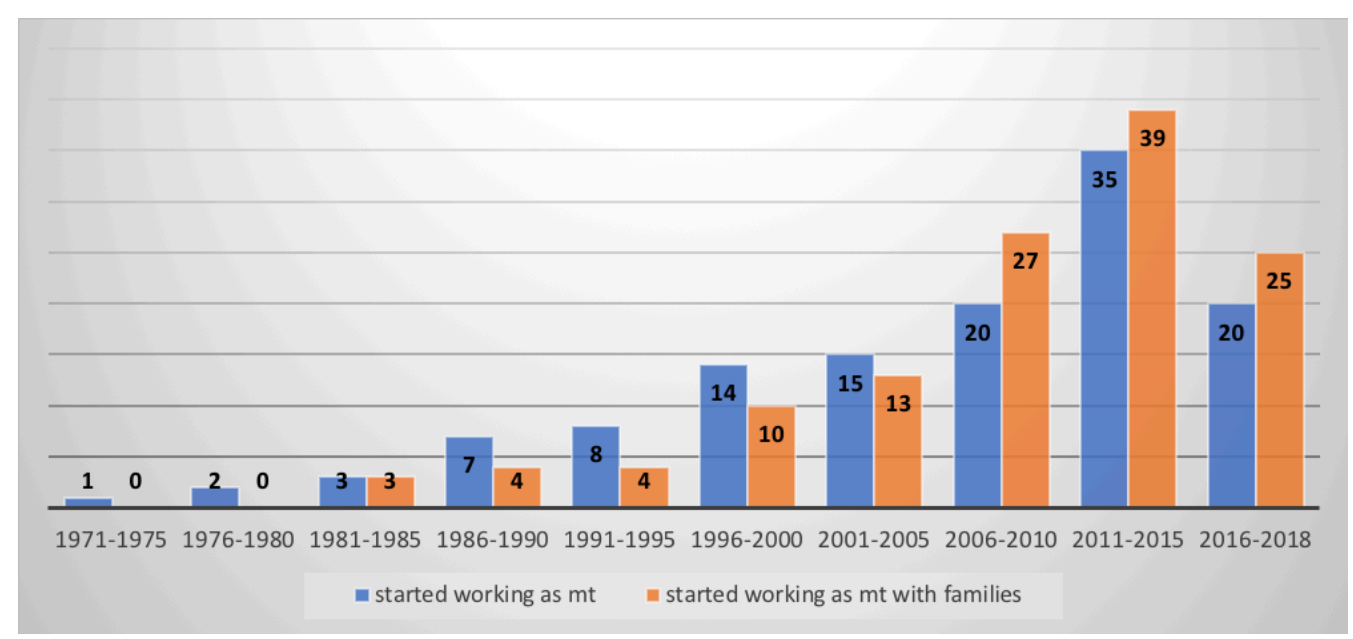

Figure 2

Compairing the years between starting to work as music therapist and starting to work with families in music therapy

sample, the more experienced music therapists reported working with families as early as the 1980s (Figure 2).

\section{Clinical Population}

Music therapy practice is often highly varied, and this trend was reflected in the data. Many of the respondents reported that they work with several clinical populations. Therefore, there was a total of 381 selected answers to question 11 . When "other" responses were added retrospectively to the initial options, there 415 populations selected by 124 participants (Figure 3).

According to these results, disability was the largest clinical population in which music therapists work with families. Of these, $16.9 \%(n=70)$ of the respondents work with preschool aged children with disabilities and $13.7 \%(n=57)$ with school aged children with disabilities. Mental health was the next most common population for 


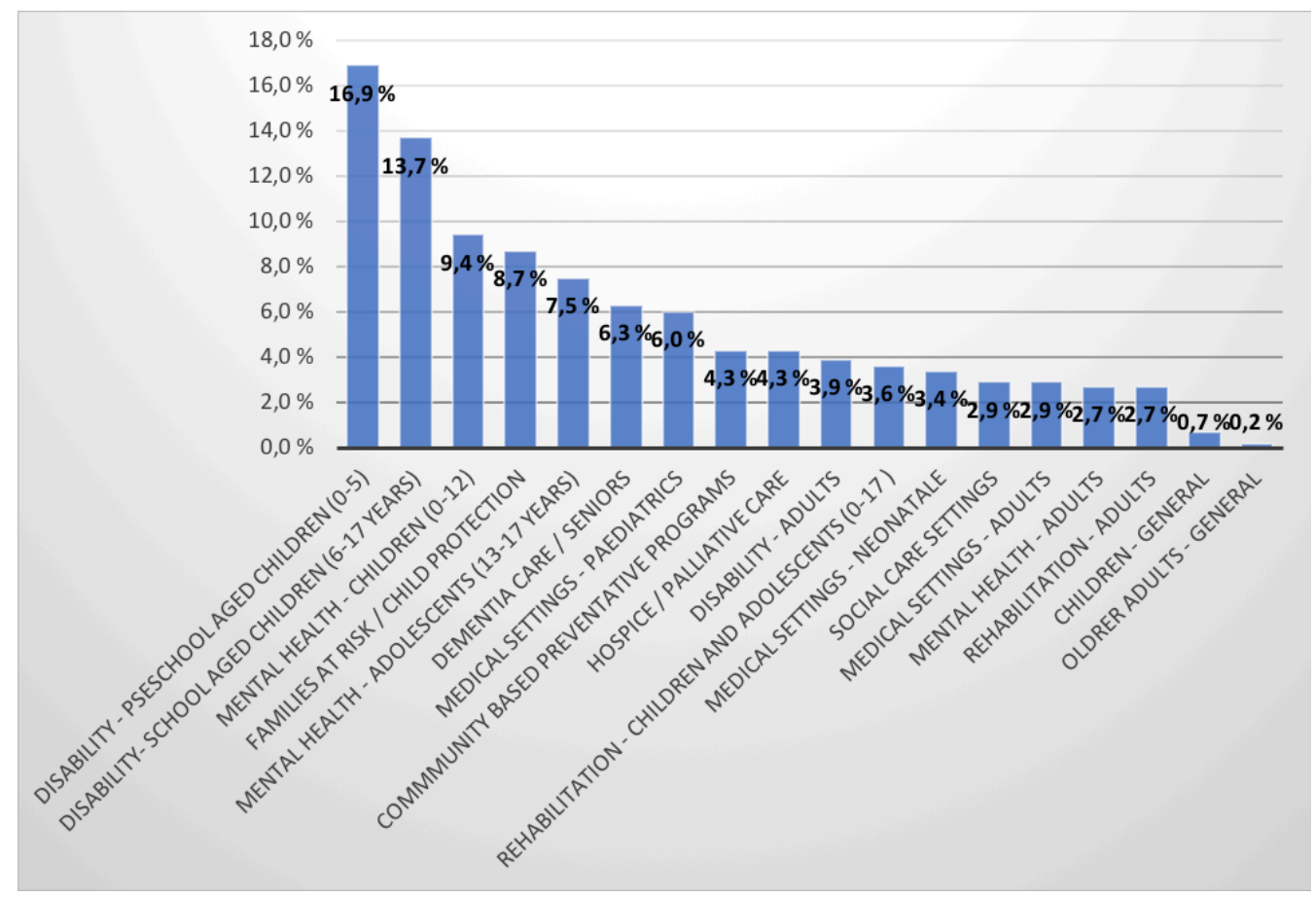

Figure 3

Clinical population

music therapists working with families, with $9.4 \%(n=39)$ working with children, $7.5 \%(n=31)$ working with adolescents, and $2.7 \%(n=11)$ working with adults. Families at risk/child protection were also highly represented, with $8.7 \%(n=36)$ of music therapists working with this population.

From the "other - please describe" comments, three new categories were constructed, including $4.3 \%(n=18)$ of respondents who indicated that they worked with families in hospice or palliative care settings. However, other responses were more difficult to categorise where they did not refer to a specific clinical population, such as "special needs," "public school" or "mainstream children's center and school." The authors considered that these answers could be referring to children with behavioural problems, ADHD or learning disabilities or children with no specific diagnosis. Therefore, a "Children - general" category was established. In a similar way, "Older adults - general" was added as a category even though this was represented by only $0.2 \%$ of the respondents. Additionally, respondents indicated that they work with populations including emergency settings post-disaster and conflict, military families as well as asylum-seeking families.

While there is great variety, when clustering the results into broader categories, the dominance of certain populations became more apparent. According to these results, $35 \%$ of music therapists working with families work in the field of disability, and $20 \%$ in mental health (Figure 4). If the categories of families at risk/child protection and social care settings were combined, $12 \%$ of the respondents could be classified as working in this area. Similarly, $13 \%$ of participants work in medical settings with clients of all ages. Dementia care/seniors and hospice/palliative care may not be easily combined, since end-of-life care involves clients of multiple age groups.

Taking this broader view one step further, an approximate analysis of the age distribution could also be made. Based on the population descriptions, it seems that $79 \%$ of the respondents work with children and adolescents, while $21 \%$ of music therapists surveyed work with adults (Figure 5). To avoid ambiguity, the categories of hospice/ palliative care, community based preventative programs, and social care settings were left out from this age analysis because the exact age was able to be determined. 


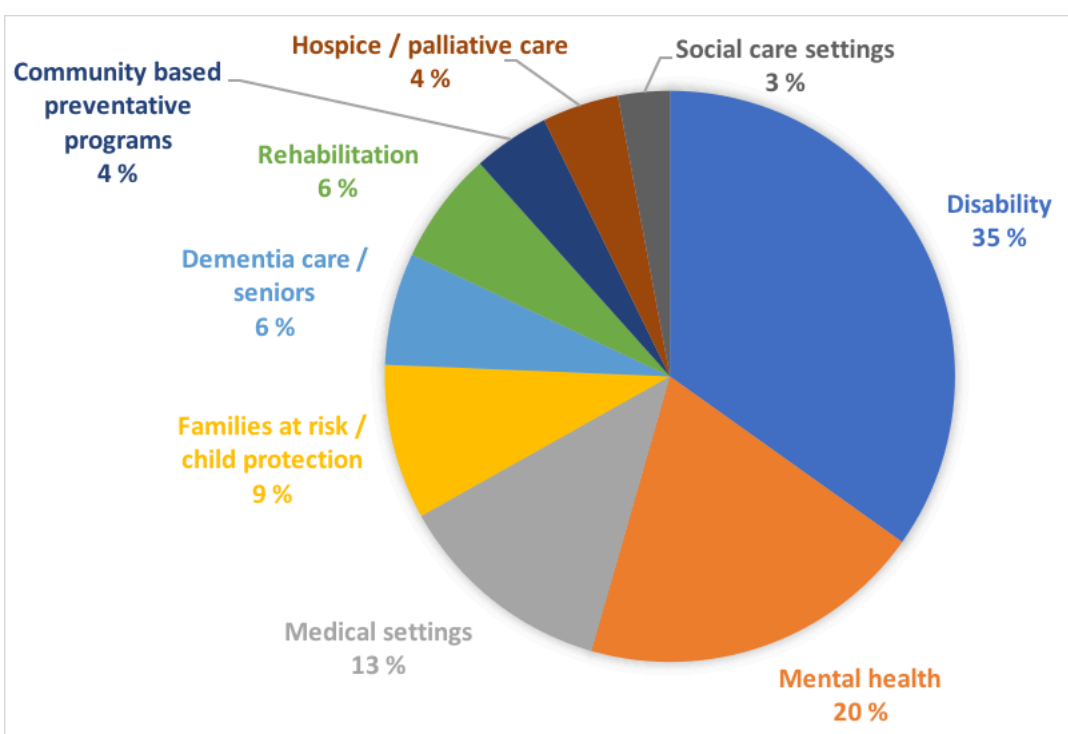

Figure 4

Clinical population clustered

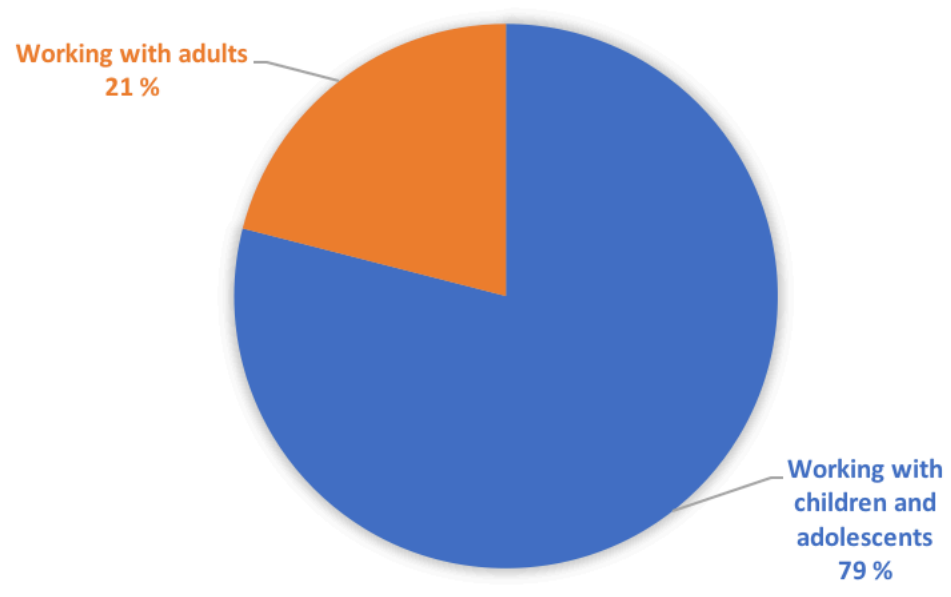

Figure 5

Working with children/adults

\section{Clinical Setting}

The survey findings revealed that music therapy with families commonly takes place in community settings ( $n=54$; Figure 6 ). This category included i.e., music centres, music schools, community centres, and libraries. Hospital/medical settings, including hospice units $(n=53)$ and music therapy taking place at the client's home $(n=50)$ were also common. Specialist multidiciplinary services clinics $(n=24)$ included i.e., family rehabilitation centres and centres specialized in pregnancy, birth and early parenting. From the "other - please describe" comments, one new category was constructed: "Residential care facility for older adults." This category includes rest homes, nursing homes, assisted living communities and seniors home.

\section{Theoretical Framework}

Respondents indicated there was a large variety of theoretical frameworks applied to working with families (Figure 7). The responses indicate that each music therapist on average has three theoretical influences in their work. The humanistic framework was 


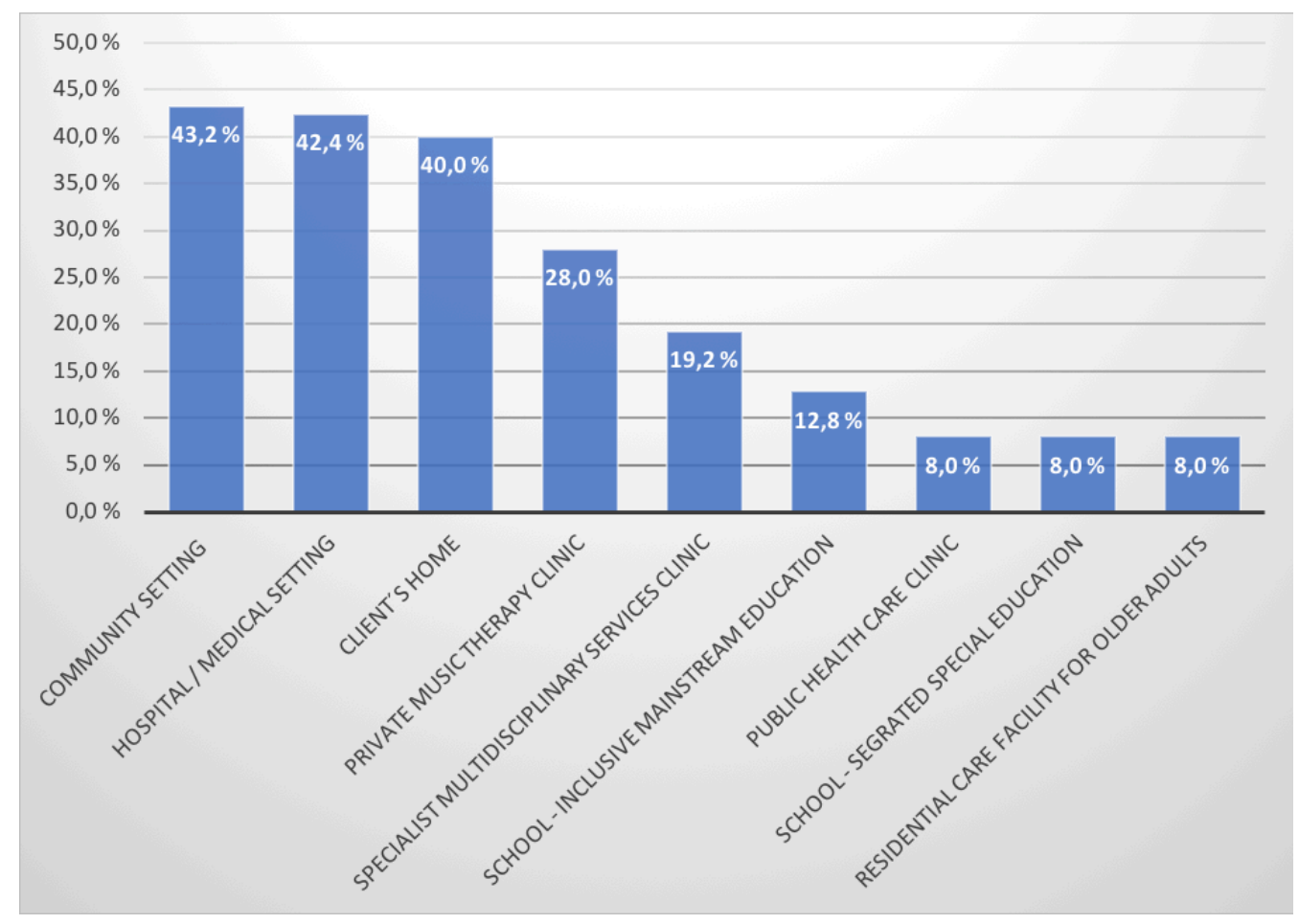

Figure 6

Where do sessions take place

the most salient with $72 \%(n=90)$ of people indicating they align with this theory, including more specific approaches such as wellness based theories, validation therapy, and existential and phenomenological viewpoints. Developmental frameworks ( $n$ $=55)$ included play-based interventions and Floortime. Psychodynamic $(n=48)$ and resource oriented $(n=41)$ approaches were both well represented. Integrative $(n=$ 39) and systems/ecological oriented $(n=34)$ were nearly equally often mentioned as well as neurological $(n=19)$ and behavioral $(n=19)$ approaches.

From the "other - please describe" comments, five new categories were constructed. Three respondents described their approach as based on attachment theory. The authors debated whether this approach could be considered part of psychodynamic theory, but ultimately could not be sure given that the participants had included this answer within the "other" response. The "narrative" framework $(n=3)$ was also included as a new category. Only one respondent described "mentalization," and similarly the authors debated whether this approach could be considered as belonging to the psychodynamic framework. However, it seemed important to emphasize this approach, especially when working with families, and therefore it remained as a separate category. "Music-centered" $(n=1)$ and "interactive" $(n=1)$ approaches were included as their own categories as well since both seemed to accent particular features of their framework.

\section{Clinical Methods and Techniques}

For question 14, "What music therapy methods do you use when working with families in music therapy sessions," multiple answers were possible resulting in 634 choices from the 125 participants. This equates to an average of 5 methods per person, suggesting that a large variety of music therapy methods are relevant to working with families. The most commonly reported methods were improvisation with instruments $(n=115)$, singing pre-composed songs $(n=101)$ and structured activities with musical instruments $(n=91)$. Also, improvisation with voice $(n=85)$, music listening $(n=79)$, music and movement $(n=78)$ and song writing $(n=63)$ were commonly reported. 


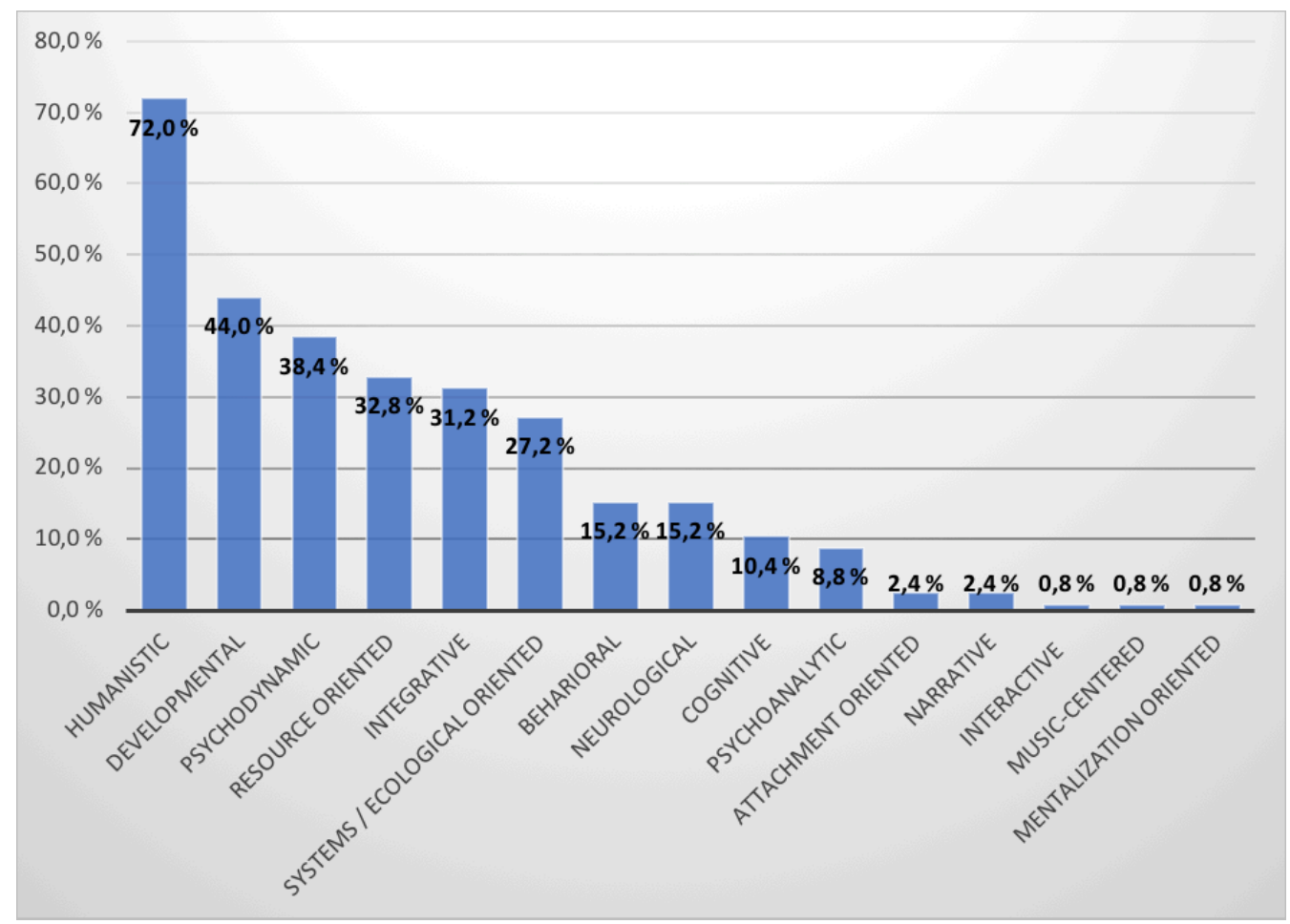

Figure 7

Theoretical frameworks

From the "other - please describe" comments, two new categories were constructed. The first was integrative methods and integrating musical activities, where different methods were used in a holistic and dynamic way depending on the needs of the family. The second was including other non-musial methods in music therapy sessions, such as the use of pictures, play, meditation, story telling, and Eye Movement Desensitization and Reprocessing (EMDR).

These results could also be clustered into broader categories as follows: 1) singing, including pre-composed songs and improvisation with voice; 2) playing instruments, including structured activities with musical instruments and improvising with instruments; 3) music listening, including Guided Imagery and Music (GIM); 4) music and movement; 5) song writing; and 6) other. When responses were analysed from this broader viewpoint, singing (29\%) and playing instruments (33\%) together accounted for $62 \%$ of the data (Figure 9).

According to this survey, "consultation and discussion" was the most popular nonmusic-based technique, with $82.2 \%(n=104)$ of respondents stating they use this approach with families in music therapy sessions (Figure 10). This approach included several ways of working, including therapeutic discussion, verbal processing, reminiscing and life review. Imaginative play with toys $(n=53)$, art-based methods $(n=48)$, and playing games with rules $(n=41)$ were also used frequently.

"Techniques from other therapeutic approaches" was a new category developed during the analysis of the free-text responses. This category $(n=9)$ included approaches such as Theraplay ${ }^{\circledR}$, narrative exposure therapy, Adaptive Mentalization-Based Integrative Treatment (AMBIT) and Mentalization Based Treatment (MBT), trauma-informed care approaches, and cognitive therapy. The integrative methods category was also retrospectively added to acknowledge the flexible, shifting and dynamic way of working described by one respondent. In addition, two other categories were added based on the free-text responses, including: multisensory activities $(n=1)$, meaning multisensory actions (lifting, waving); and interactive play $(n=1)$ including the use of early childhood play/games between the child and the carer. 


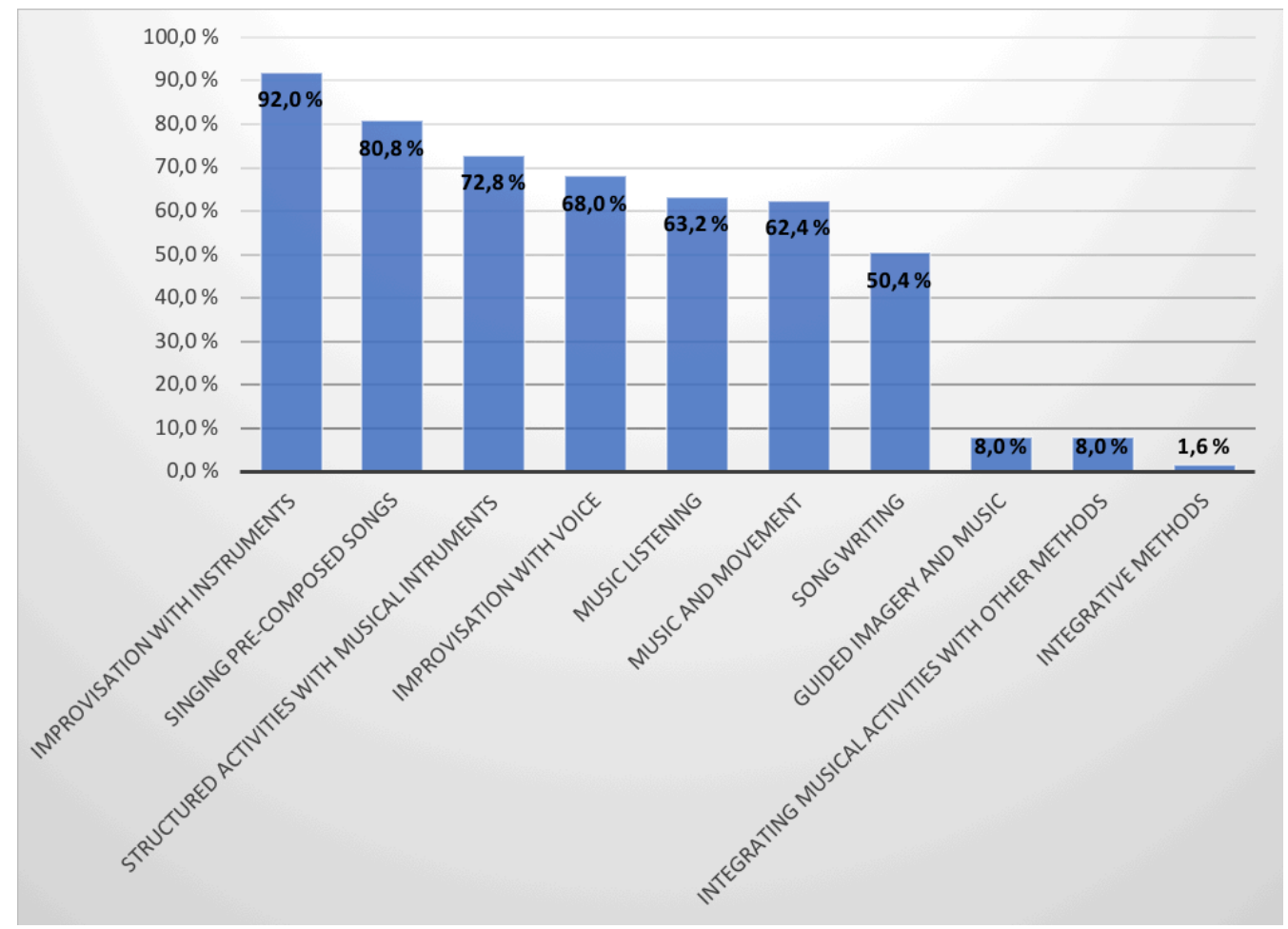

Figure 8

Music therapy methods used with families

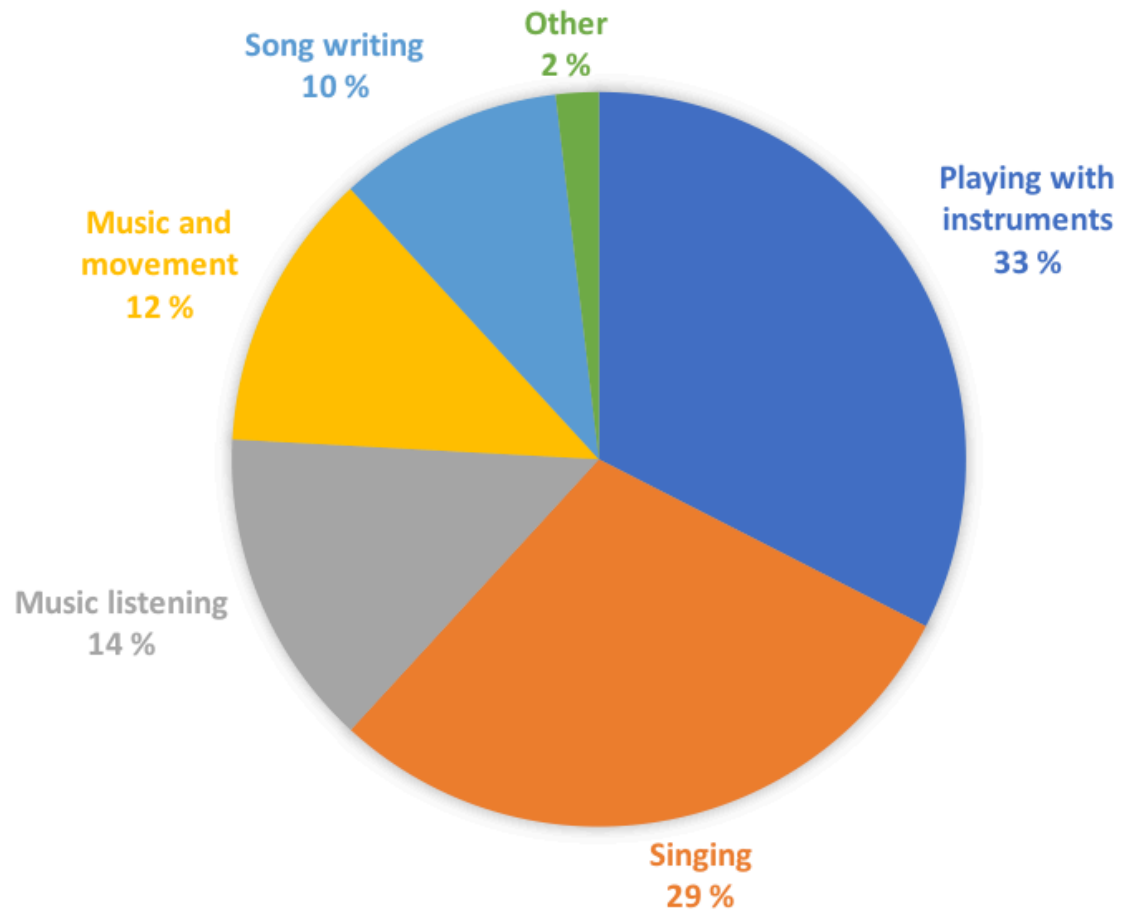

Figure 9

Music therapy methods clustered

\section{Clinical Models}

The most selected answer to question 16 "Which of the following models best describe your work", was "family members are active participants in music therapy sessions with the child/adult client" $(93.6 \%, n=117)$. Forty of the respondents $(32 \%)$ reported that family members were present but not active in music therapy sessions. Taking 


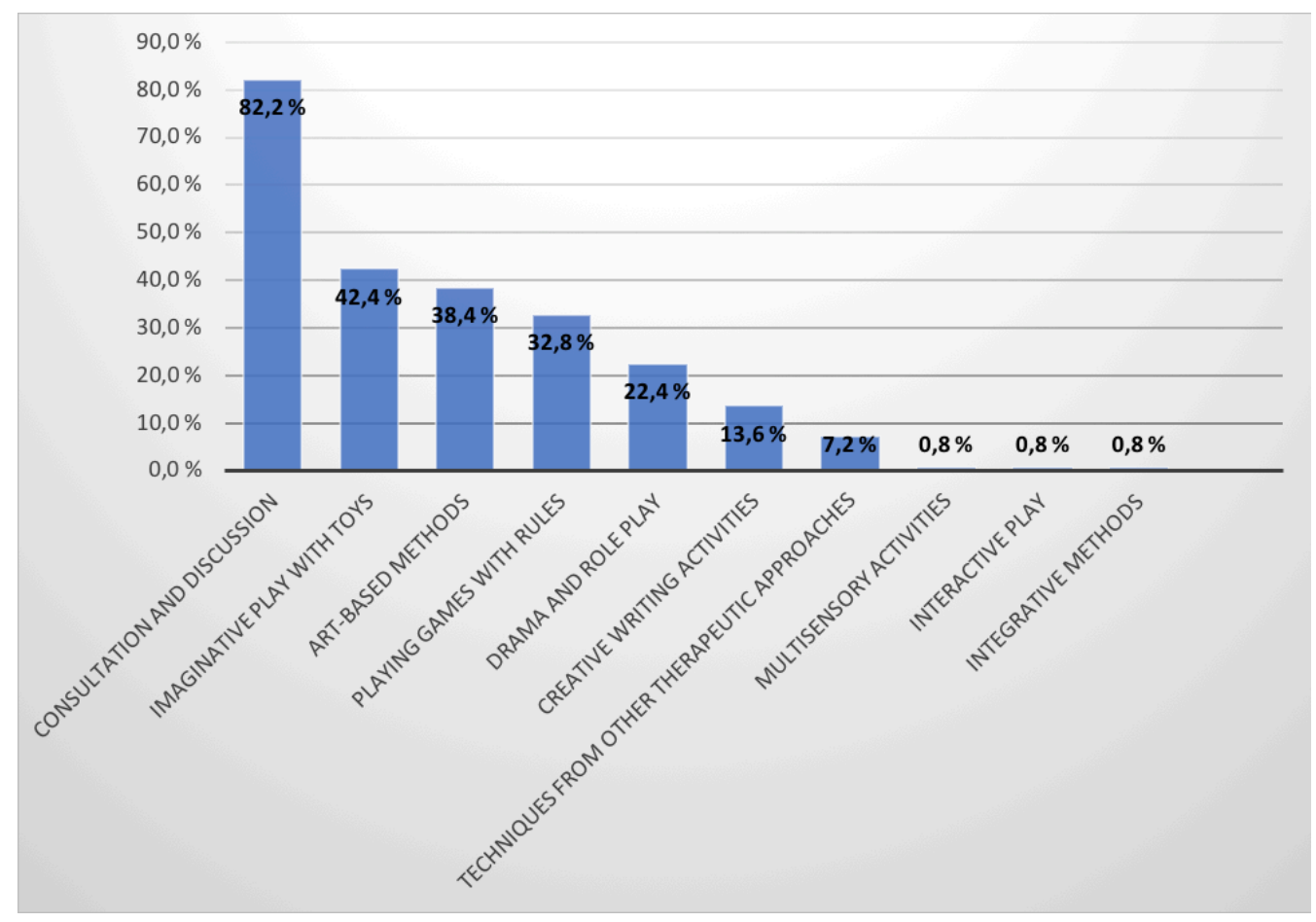

Figure 10

Non-music based therapy techniques used with families

these two categories together, it is therefore much more common for family members to be present in the music therapy session with the child/adult client than not. Even so, 33 participants (4.8\%) reported that they conducted "separate/additional counselling sessions" for family members.

Analysis of the free-text responses highlighted that people also use a combination of models. Therefore, a new category of "integrative methods" was created to reflect this approach. Further, in the free-text response, one person described a model where family members participated in separate music therapy sessions provided by another music therapist. A new category was created to capture this reponse.

When these results were clustered into broader categories, results showed that $77.0 \%(n=157)$ of respondents stated that family members pariticipate in music therapy sessions, either actively or more passively. Counselling sessions provided by the same music therapists in individual or group meetings appeared in $19.1 \%(n=39)$ of the answers. Family members observing the session from outside the therapy room, along with family members'who received separate music therapy sessions, were clustered into the "Other" category and covered 3.9\% $(n=8)$.

With the earlier clustered data from question 11 indicating that $79 \%$ of respondents work with children or adolescents, it is perhaps not surpising to see that $86.4 \%$ participants indicated that the parent(s) $(n=108)$ were most often present in music therapy sessions, followed by sibling(s) $(43.2 \%, n=54)$. For those music therapists working with adult clients, the data also shows that the partner/spose is included $32.8 \%$ of the time $(n=41)$. There may also be other extended family members $(n=34)$ and grandparent(s) $(n=30)$ included in music therapy sessions.

\section{Counselling Sessions}

The question concerning counselling aimed to map how frequently separate counselling sessions with family members occur. However, it should be noted that $54.4 \%$ ( $n$ $=68$ ) of respondents stated that the question was not relevant to their work. Therefore, the actual analysis included only 59 answers (Figure 14). According to this data, separate sessions for family members typically take place less frequently than sessions 


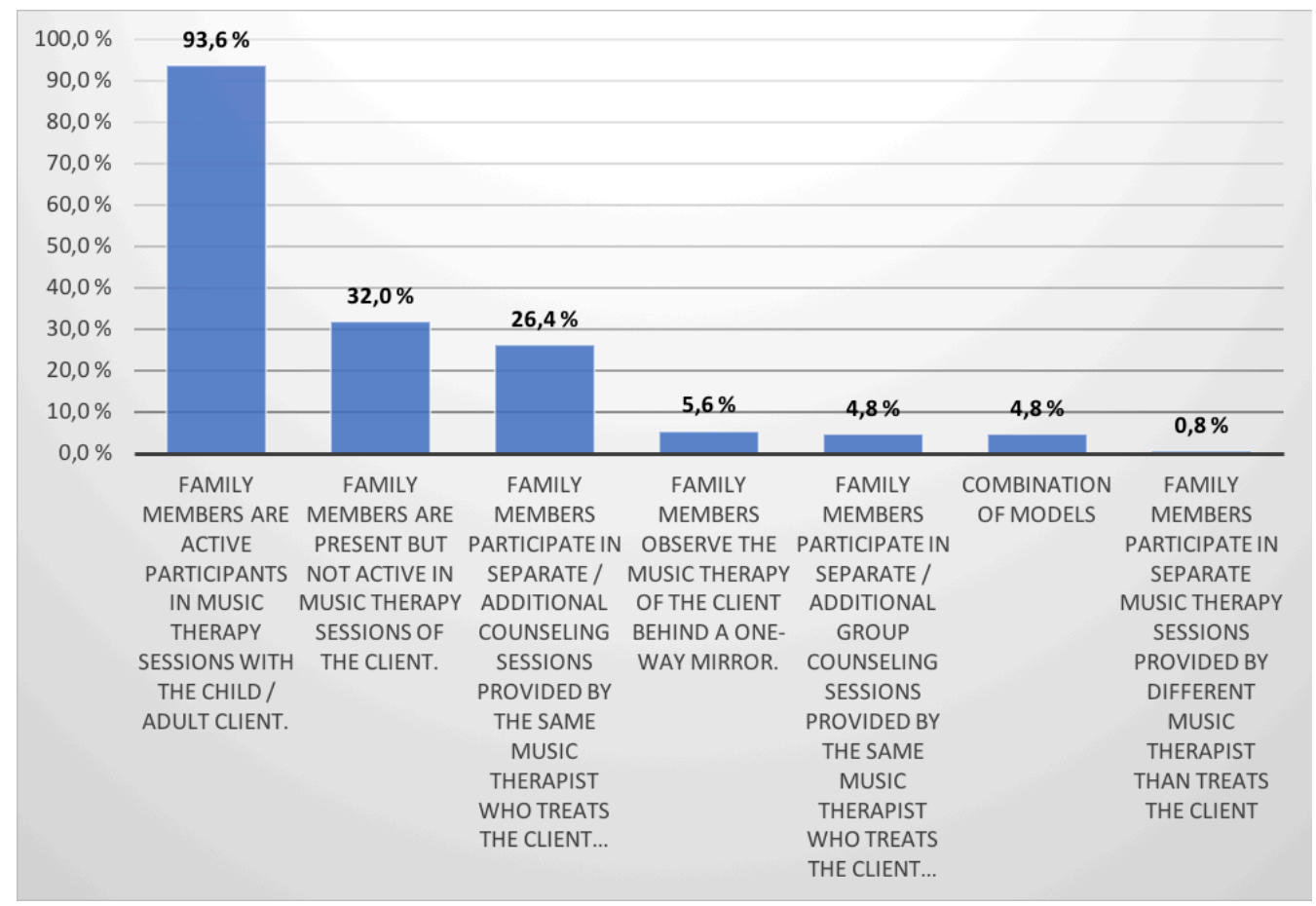

Figure 11

Models best describing work with families

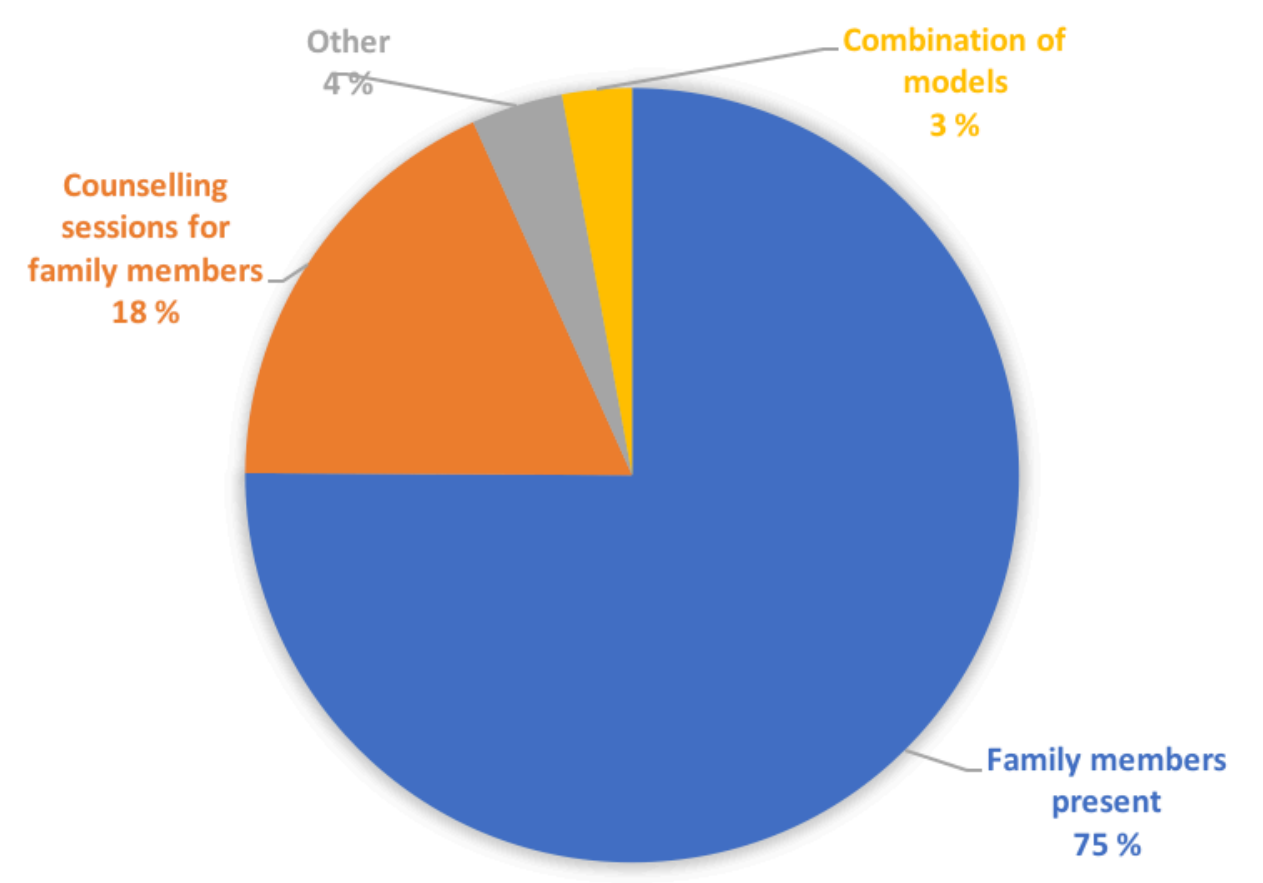

Figure 12

Music therapy models clustered

with the client $(n=39)$. Only one respondent $(n=1)$ mentioned that the counselling sessions take place more frequently than sessions with the child/adult client. One new category was constructed based on the free-text analysis: The frequency varies depending on the client's needs $(n=6)$. Again, in this question music therapists seemed to advocate for flexibility in their practice and explained that the frequency depends on the demands, goals, context and needs of different cases. 


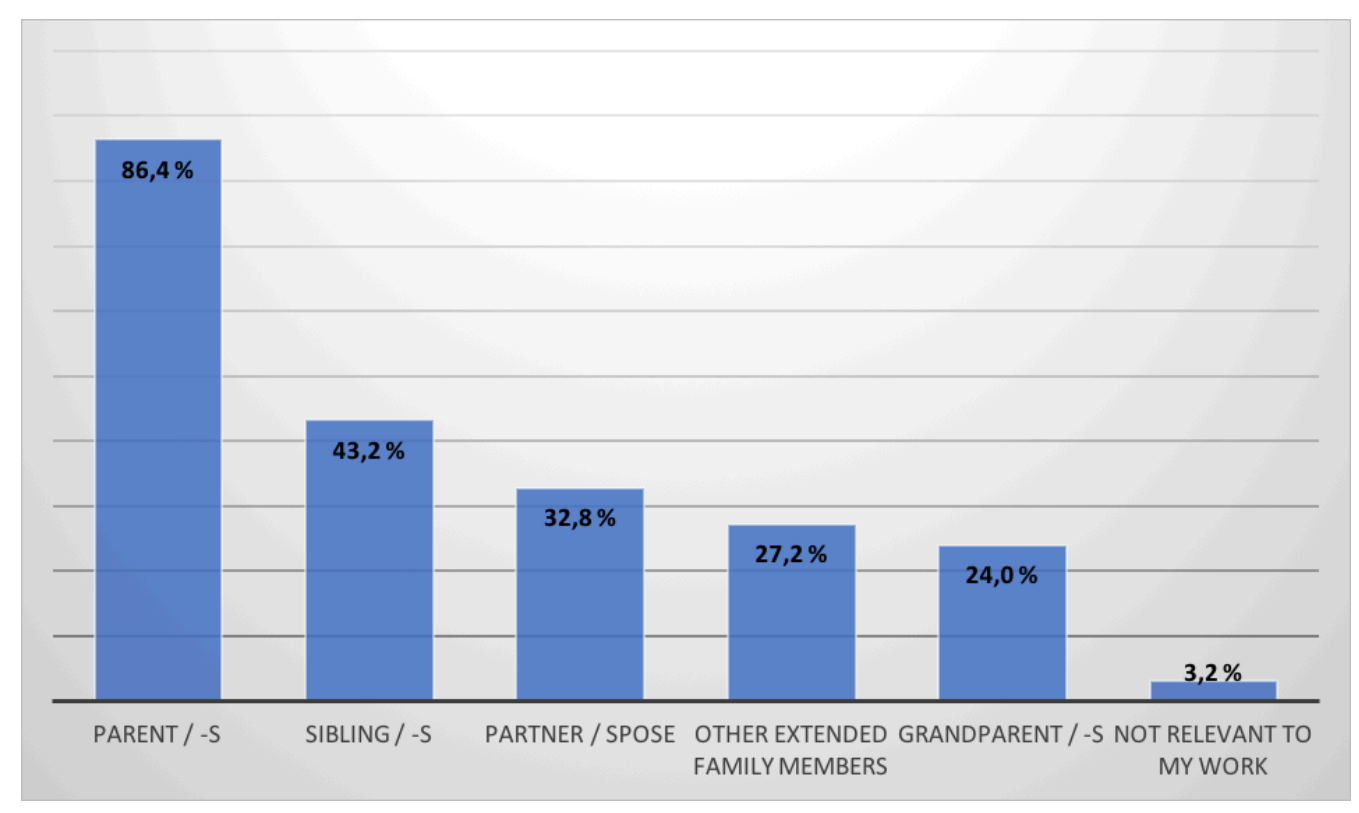

Figure 13

Who attends music therapy sessions with child/adult client?

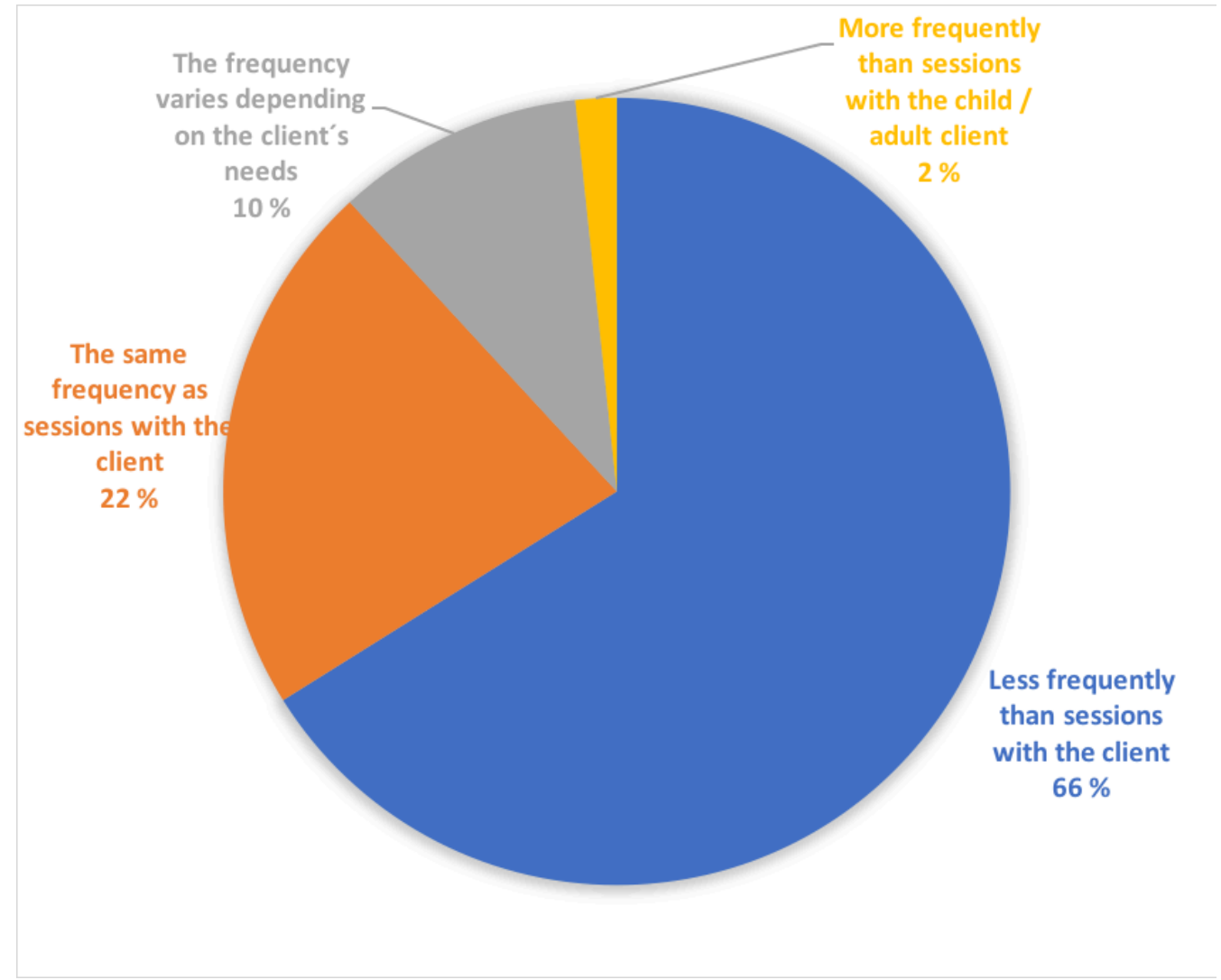

Figure 14

Frequency of counselling sessions $(n=59)$

When asked about the most common techniques used in these separate counselling sessions, discussion and consultation was highly reported $(n=68$; Figure 11$)$. Music therapy methods were also used widely within counselling sessions. Improvisation with instruments $(n=38)$, music listening $(n=28)$, song writing $(n=24)$ and improvisation with voice $(n=22)$ were all mentioned. From the non-music-based techniques, the use of video feedback $(n=19)$ was most common. However, similar to 


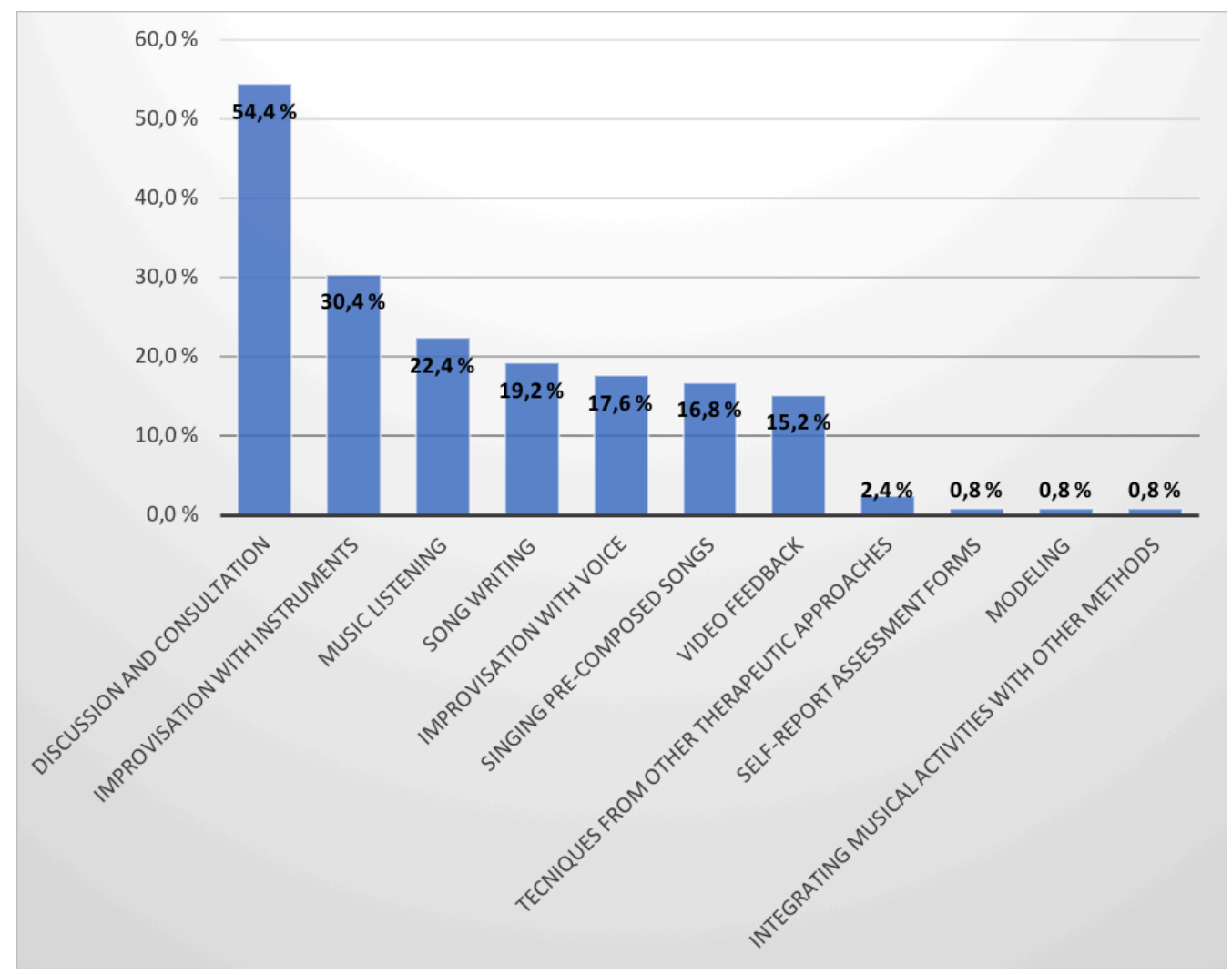

Figure 15

Techniques used in counselling sessions

the question above, $40 \%(n=50)$ of respondents chose the option "not relevant to my work."

While analysing the free-text response, four new categories were constructed: techniques from other therapeutic approaches $(n=3)$ which included Mentalization Based Treatment (MBT) for families, breathing activities, and mindfulness. Modelling was formed as a category of its own $(n=1)$, including modelling Applied Behavior Analysis (ABA) techniques. The use of a self-report assessment form, Spence Children's Anxiety Scale (SCAS) for parents was placed in an idependent category of self-report assessment forms $(n=1)$. Using movement to music was categorized in the integrating musical experiences with other methods category $(n=1)$.

\section{Role of the Music Therapist}

Question 20 provided opportunity for a free-text response: "How would you describe your role as a music therapist working with families?" There were 105 responses to this question, which underwent a qualitative content analysis. The analysis generated 159 codes which were then further grouped into 12 categories. Table 3 shows the final categories along with the numbers of individual codes within each category and a summary description incorporating exemplars of the words used by the respondents.

A descriptive quantitative analysis revealed that the first category "To share their expertise: as a counsellor, teacher or guide" included $45.7 \%$ of the responses. The role of the music therapist was described as "to support" in $35.2 \%$ of answers, whereas the role "to provide, create, and offer" followed with $25.7 \%$ of responses.

Similar to responses to previous questions, some respondents described that their role varied depending on the context, clients and their needs $(n=7)$. A small number of respondents emphasised that their role is to be a therapist for the parents $(n=3)$ or both to the child and the parent $(n=1)$.

Overall, these 12 categories describing how music therapists view their role in working families could be further distilled in order to highlight the main features. The sur- 
Table 3

The role of the music therapist when working with families ( $n=$ number of codes)

\begin{tabular}{|c|c|}
\hline Category & Description of category \\
\hline $\begin{array}{l}\text { To share } \\
\text { their exper- } \\
\text { tise: as a } \\
\text { counsellor, } \\
\text { teacher or } \\
\text { guide ( } n= \\
48 \text { ) }\end{array}$ & $\begin{array}{l}\text { The stance of the therapist is more on the expert level. The therapist knows something } \\
\text { which they want to share with the family. It might be providing direct advice, modelling, } \\
\text { techniques, or knowledge of i.e., disablity or trauma. }\end{array}$ \\
\hline $\begin{array}{l}\text { To support } \\
(\mathrm{n}=37)\end{array}$ & $\begin{array}{l}\text { Therapist is a supporter concerning development, interaction and relationship. They give } \\
\text { support on an emotional level as well, i.e., in grief and in the form of debriefing. }\end{array}$ \\
\hline $\begin{array}{l}\text { To provide, } \\
\text { create and } \\
\text { offer }(n= \\
\text { 27) }\end{array}$ & $\begin{array}{l}\text { The role of the therapist is to provide a supportive and safe place and space. The therapist } \\
\text { is a provider of music, contact and interaction, as well as new experiences. Therapist may } \\
\text { also be a provider of memories and a bridge through loss. The therapist creates space and } \\
\text { atmosphere in addition to contact and interaction with meaningful, shared experiences. } \\
\text { The therapist offers room and space where music can be used as a bridge or to make } \\
\text { memories. }\end{array}$ \\
\hline $\begin{array}{l}\text { To facilitate } \\
(n=22)\end{array}$ & $\begin{array}{l}\text { The role of the therapist is to facilitate i.e., engagement, interaction and communication, } \\
\text { development, attachment and bonding. In addition, they may facilitate normalization, } \\
\text { space, understanding, solutions, and emotions. }\end{array}$ \\
\hline $\begin{array}{l}\text { To care and } \\
\text { help }(n=21)\end{array}$ & $\begin{array}{l}\text { The therapist takes care and helps with emotions, answers to the needs of the family. Also } \\
\text { the therapist may help to build new understandment and knowledge. }\end{array}$ \\
\hline $\begin{array}{l}\text { To empow- } \\
\text { er, encour- } \\
\text { age and } \\
\text { give posi- } \\
\text { tive in- } \\
\text { sights ( } n= \\
\text { 18) }\end{array}$ & $\begin{array}{l}\text { The therapist's role may be to empower the family and give new positive viewpoints of the } \\
\text { child. The therapist can help the family to find and be aware of their strengths and re- } \\
\text { sources and reinforce the identity of the clients. The role of the therapist is to encourage } \\
\text { and challenge the family. }\end{array}$ \\
\hline $\begin{array}{l}\text { To enable } \\
(n=15)\end{array}$ & $\begin{array}{l}\text { Therapist enables connection, interaction and communication. In addition, the therapist } \\
\text { can enable peer support, new ways of seeing the child, performace for parents and memo- } \\
\text { ry making. }\end{array}$ \\
\hline $\begin{array}{l}\text { To promote } \\
(n=11)\end{array}$ & $\begin{array}{l}\text { The role of the therapist is to promote integration from therapy to everyday life. The ther- } \\
\text { apist promotes wellbeing, relationships and communication. }\end{array}$ \\
\hline $\begin{array}{l}\text { To be a } \\
\text { companion } \\
(n=6)\end{array}$ & $\begin{array}{l}\text { The therapist is a companion, co-worker, collaborator and contributor with the family. The } \\
\text { therapist may see their role to be part of the group. }\end{array}$ \\
\hline $\begin{array}{l}\text { To collabo- } \\
\text { rate with } \\
\text { networks ( } n \\
=5 \text { ) }\end{array}$ & $\begin{array}{l}\text { The therapist may be seen as a collaborator by liasing with other professionals, and han- } \\
\text { dling referrals. They may be a mediator for the client's wishes or providing material for } \\
\text { fund-raising. }\end{array}$ \\
\hline $\begin{array}{l}\text { To collect } \\
\text { information } \\
(n=4)\end{array}$ & $\begin{array}{l}\text { The therapist may have a role to explore or identify issues conserning development or } \\
\text { emotions. Also, the therapist can be a receiver of information. }\end{array}$ \\
\hline $\begin{array}{l}\text { To regulate } \\
(n=4)\end{array}$ & $\begin{array}{l}\text { The therapist's role may be seen as a regulator of emotions. The therapist helps the family } \\
\text { to cope with difficult emotions and may serve as a container. }\end{array}$ \\
\hline
\end{tabular}

vey results showed that the role of the music therapist was most often related to: 1) Supporting family members to interact and communicate; 2) containing, regulating and holding emotions; 3 ) promoting family relationships by fostering attachment and bonding; 4) facilitating accessible music experiences; 5) empowering and supporting parent; and 6) fostering and supporting development. 


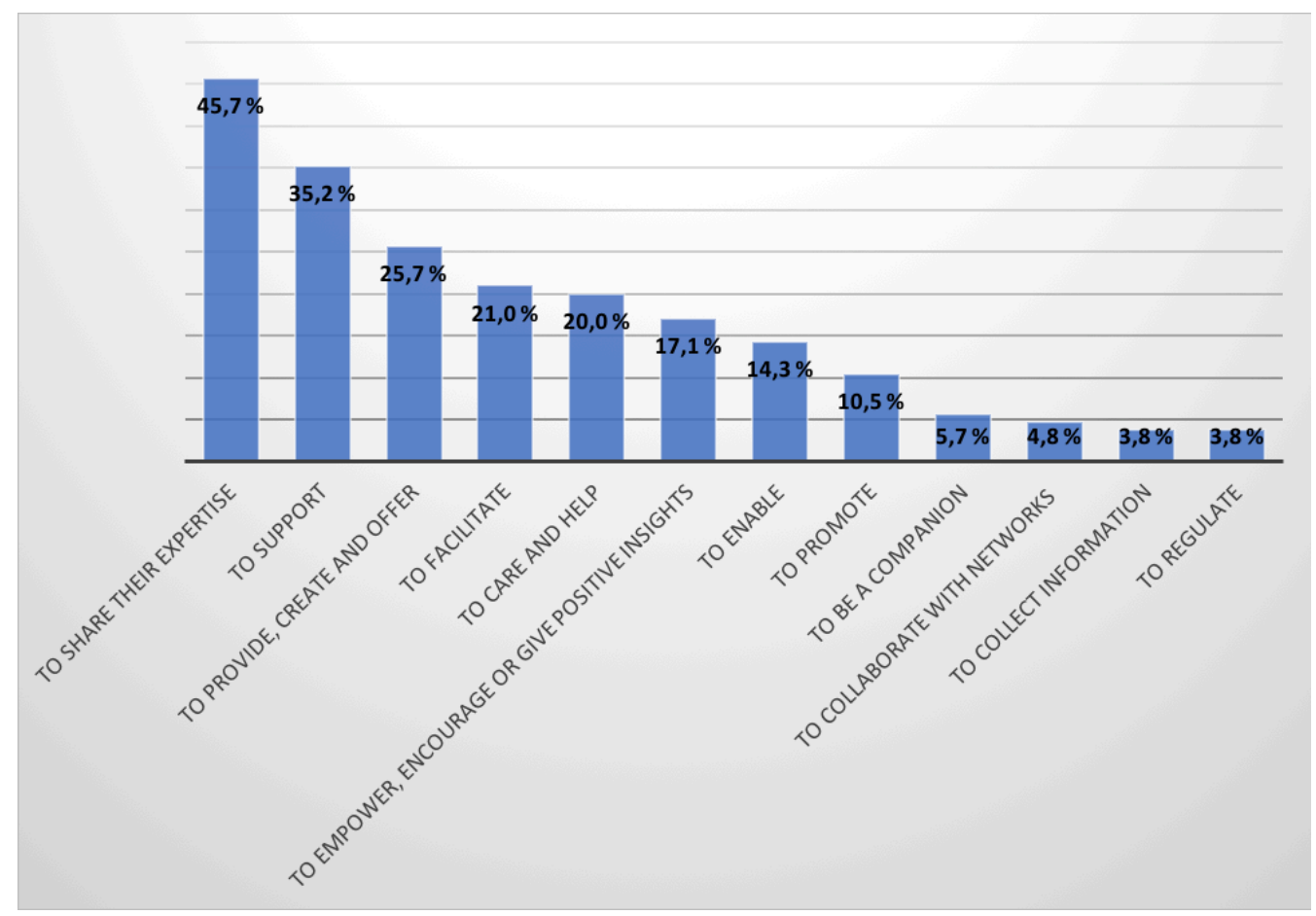

Figure 16

Role of music therapist when working with families $(n=105)$

\section{Existing Training Courses in Working with Families}

In response to question 21, respondents identified that there are some specialist training courses in working with families in different countries. The free-text responses included the following training courses: assesment of parent-child interaction (APCI) by Lindahl-Jacobsen (i.e., Jacobsen et al., 2014) originally developed in Denmark; a short course in family centered music therapy and dialogic parent counselling by Tuomi and Jordan-Kilkki from Finland (Jordan-Kilkki \& Tuomi, 2016); specialist courses focused on music therapy in hospice settings (no trainers or names were provided); a short course in music therapy and families from Spain; neonatal intensive care unit (NICU) music therapy training (www.nicumusictherapy.com); and the "Sprouting Melodies" training model available in the USA (www.sproutingmelodies.com). In addition, respondents broadly described workshops, visiting lecturers and short courses taking place in various locations around the world for music therapists working with families.

\section{Perspectives on Future Content for Training in Music Therapy with Families}

In response to question 22, there were 92 participants who provided their perspective, insights and ideas. The high level of engagement in this question perhaps indicates the passion these respondents have for promoting further skills and training in music therapy with families. From these 92 responses, 120 codes were identified through a Qualitative Content Analysis, and from these codes 11 categories were formed. Some respondents indicated that short courses $(n=5)$ and advanced training seminars $(n=$ 5) for qualified music therapists are needed; however, others indicated that training should also take place within clinical placements $(n=4)$ and as part of initial music therapy qualification courses $(n=3)$.

The categories describing the focus of future training courses in music therapy with families could be clustered into three main themes: Theory, Practice and Context (Table 4). 
Table 4

What should be included in music therapy training programs and continuing education $(n=92)$

\begin{tabular}{|l|l|l|}
\hline \multicolumn{2}{|c|}{ Main themes } \\
\hline \multicolumn{1}{|c|}{ Theory $(n=85)$} & \multicolumn{1}{|c|}{ Practice $(n=74)$} \\
\hline $\begin{array}{l}\text { Theoretical knowledge }(n= \\
47)\end{array}$ & Techniques and methods $(n=40)$ & Context $(n=12)$ \\
\hline Family work $(n=31)$ & Verbal facilitation $(n=23)$ & $\begin{array}{l}\text { Working collaboratively }(n= \\
4)\end{array}$ \\
\hline Parental support $(n=7)$ & Music methods $(n=7)$ & Relevant supervision $(n=3)$ \\
\hline & $\begin{array}{l}\text { Working in the home \& community }(n= \\
4)\end{array}$ & \\
\hline
\end{tabular}

\section{Theory}

Overall, theoretical knowledge $(n=47)$ was emphasised as an important part of training and continuing education. Respondents specifically mentioned the need to include theoretical perspectives around cultural issues $(n=2)$, child developmental $(n=2)$, philosophy $(n=2)$, attachment issues $(n=1)$ and community-oriented work $(n=1)$.

Family centered theory $(n=31)$ was a prominent category that suggests respondents consider that music therapists need to be better informed about working within these principles. This category includes the specific examples of family dynamics ( $n=$ 7), the role of family members and the therapist $(n=5)$, and the value of family inclusion $(n=4)$. Family therapy approaches more specifically were mentioned by three respondents.

Similarly, parental support was described specifically by seven participants. The repondents expressed the need to have more specific information about how to work with parents $(n=2)$, understand parental stress $(n=1)$, promote parental responsiveness $(n=1)$ and support parental relationship in musical communication $(n=1)$.

\section{Practice}

The respondents expressed a need for more training in specific techniques and methods relevant to working with families $(n=31)$. Further, they saw value in receiving detailed practical guidance, excercises, activities and interventions $(n=8)$, while techniques and strategies $(n=6)$, assessment tools $(n=4)$, and video assisted work ( $n$ $=4$ ) were also described. In the more specific answers, some respondents expressed a desire to develop specific techniques and skills such as drama and role play $(n=3)$, documentation skills $(n=1)$, and self-care $(n=1)$.

Another important practice skill identified by participants related to the need to develop their verbal facilitation skills $(n=23)$. More specifically, respondents identified the need for training in conversational techniques, such as consultation and counselling skills $(n=15)$, feedback techniques $(n=2)$, reflective and reflexive practices $(n=2)$ and interviewing skills $(n=1)$.

Seven respondents specifically mentioned the need for more training in music skills. Of these, music improvisation $(n=2)$, supporting interactive music interventions between family members $(n=2)$ and information about typical musical development ( $n$ $=1$ ) were described.

Four respondents stated that training should also include information about how to best work outside of more traditional clinical spaces, such as in the home or other community settings $(n=4)$.

\section{Context}

The theme "contextual features" $(n=8)$ captured responses where the participants highlighted the need to better understand ethics in special educational $(n=2)$, ther- 
apeutic relationships with disabled people $(n=2)$, coping with needs of family members $(n=1)$ and the policies and procedures of child protection systems $(n=1)$. Further, respondents also saw a need to better understand how to work collaboratively with other professionals and networks involved with the family $(n=4)$. Lastly, respondents expressed the need for more opportunities for supervision of family-based clinical work in future training and education $(n=3)$.

\section{Discussion}

The 125 music therapists who participated in this survey indicated that working with families is a substantial part of their practice. While it was difficult to estimate the expected sample size, the demographic characteristics of the participants reflect those of other music therapy surveys. For example, female participants represented $90 \%$ of the respondents, which is similar to the demographics of a large international workforce survey of music therapists ( $81.6 \%$ female; Kern \& Tague, 2017). The age distribution in this survey showed that $24.4 \%$ of respondents were between $30-39$-years-old, which was similarly aligned with the demographics reported by Kern and Tague (2017) of $29.4 \%$ of respondents within the same age group.

The majority of respondents began working with families between 2006-2018, which may indicate that this is a developing field in music therapy practice. The growing body of music therapy literature and research suggests there is an increasing emphasis on family centred and relation-oriented approaches (i.e., Edwards, 2011; Kern \& Humpal, 2012; Lindahl-Jacobsen \& Thompson, 2017a; Tomlinson et al., 2012; Trondalen, 2016; Tuomi et al., 2017). With 18 different clinical populations described by participants, the results indicate that working with families is a practice approach that is becoming more relevant across the life span. While music therapy practice in neonatal care has had a long standing focus on working with families (i.e., Gooding \& Trainor, 2018; Haslbeck, 2012; Haslbeck et al., 2018; Ettenberger et al., 2017; Loewy, 2015; Shoemark et al., 2015; Teckenberg-Jansson et al., 2011), music therapy with older adults (i.e., Beer, 2017; Raglio et al., 2016; Ridder, 2017) and within end of life care also has an increasing emphasis on working with the whole family (i.e., Aasgaard, 2001; Lindenfelser et al., 2008; Lindenfelser et al., 2012; Savage \& Taylor Johnston, 2013). However, the results from this survey suggest that music therapy with families is still dominated by work with children and their parents, with $79 \%$ of respondents describing their work with children and adolescents.

Respondents reported that they draw upon a variety of theoretical frameworks, methods, techniques and models in their music therapy practice, and they incorporate these influences in a flexible and holistic way. These findings were similar to earlier surveys which found that humanism is the most commontly reported framework in the NICU (Gooding \& Trainor, 2018). While previous literature and research in music therapy with families has not emphasised psychodynamic theory within practice (Tuomi et al., 2017), 40\% of respondents selected this option. These findings are similar to the results from a broader international survey (Kern \& Tague, 2017) where $33.6 \%$ of participants reported drawing upon this theory. Similarly, common music therapy methods such as improvisation were highly reported in work with families (31.6\%) reflecting the broader music therapy literature which highlights improvisation as being key to supporting, enhancing or promoting interpersonal interaction (i.e., Haire \& McDonald, 2019; Jacobsen \& McKinney, 2015; James et al., 2015; McFerran \& Wigram, 2002; Ridder \& Gummesen, 2015). The improvisation literature also highlights the way this method can heighten emotional and relational qualities between players, which is perhaps reflected in the way these respondents described their role as being to promote relationships and contain emotions.

Some of the literature in this field describes how verbal interactions and support to parents and other family members often take place in short, informal encounters before, during and/or after the music therapy sessions rather than in separate individual or group meetings (Blauth, 2016; Gooding \& Trainor, 2018; Hodkinson et al., 
2014; Oldfield, 2011; Loth, 2008). The current study supports the literature, with only $18.1 \%$ of respondents indicating that they offer separate counselling sessions for family members. While some recent studies report benefits to parents who received separate conselleing sessions (Blauth, 2016; Gottfried 2016; Tuomi, 2017), only one respondent reported providing separate counselling sessions to family members more frequently than sessions with the child/adult client. The opportunities for different models of work are likely to be highly contextual, since the results from the survey of NICU music therapists in the USA found that $35.85 \%$ of respondents worked exclusively with parents (Gooding \& Trainor, 2018). There may also be differences in how respondents understood who the "client" is when working with families. For example, an ecological framework typically assumes the family is the client (Bruscia, 1998, p. 299) and therefore the therapist may take a broader environmental and contextual perspective (Brofenbrenner, 1979,, 1981; Crooke, 2015; Helle-Valle et al., 2017; Rolvsjord \& Stige, 2015). In this survey, $27.2 \%$ of respondents reported being influenced by systemic and ecological orientations to practice, which was lower than expected. This result may indicate that respondents more commonly focus on the individual child/adult client rather than the family as a whole.

\section{The Role of the Music Therapist When Working with Families}

The results identify that the role of music therapists working with families is broad and versatile. Lindahl-Jacobsen \& Thompson (2017b) mapped out a model for the therapist's role (also described as their "stance" or "position"), to encourage music therapists to consciously consider their approach when working with families. Their model proposed that there are three continua interacting together that the therapist might reflexively consider, including: 1) the way the therapist guides and challenges the family, ranging from a more expert position through to an equal partner; 2) the way the therapist shares knowledge and assists the family, ranging from a more directive approach through to more supportive problem solving; and 3) the degree to which the therapist engages with the family, ranging from a more distant outsider to a close insider. Rather than a protocol for how to work with families, Lindahl-Jacobsen and Thompson (2017b) stress that there is no "best" stance but merely a "best fit" for each family and context.

In reflecting on the analysis of the free-text responses to question 20 , the 12 categories could be mapped within the first two dimensions of Lindahl-Jacobsen \& Thompson's (2017b) model when they are presented as four quadrants. When considering the results through the lens of this model, music therapists adopting a more supportive-expert role are in the majority ( $n=95)$, followed by the directive-expert role $(n=57)$. However, the work cannot be interpreted in a binary way as any model might imply. The respondents in this study frequently highlighted how their approach is more likely to be dynamic and responsive to the context.

\section{Limitations}

With music therapists belonging to numerous professional groups and no single international registry for qualified music therapists available, it was difficult to estimate the expected sample size. The lack of statistical data for the profession may contribute to challenges with validity and have implications for study replication. While a variety of countries are represented in the sample, the fact that the survey was only available in English may have been a barrier to participation. Future studies should include funding to enable translation of surveys to several international lanuauges to promote participation. In addition, funding would have enabled access to resources to support recruitment and advertising which may have increased accessibility and the number of responses.

Formulating multiple choice questions for an international audience is also challenging. Despite careful consultation in the pilot stage, different traditions, terminology and cultural considerations might not have been adequately included. This 


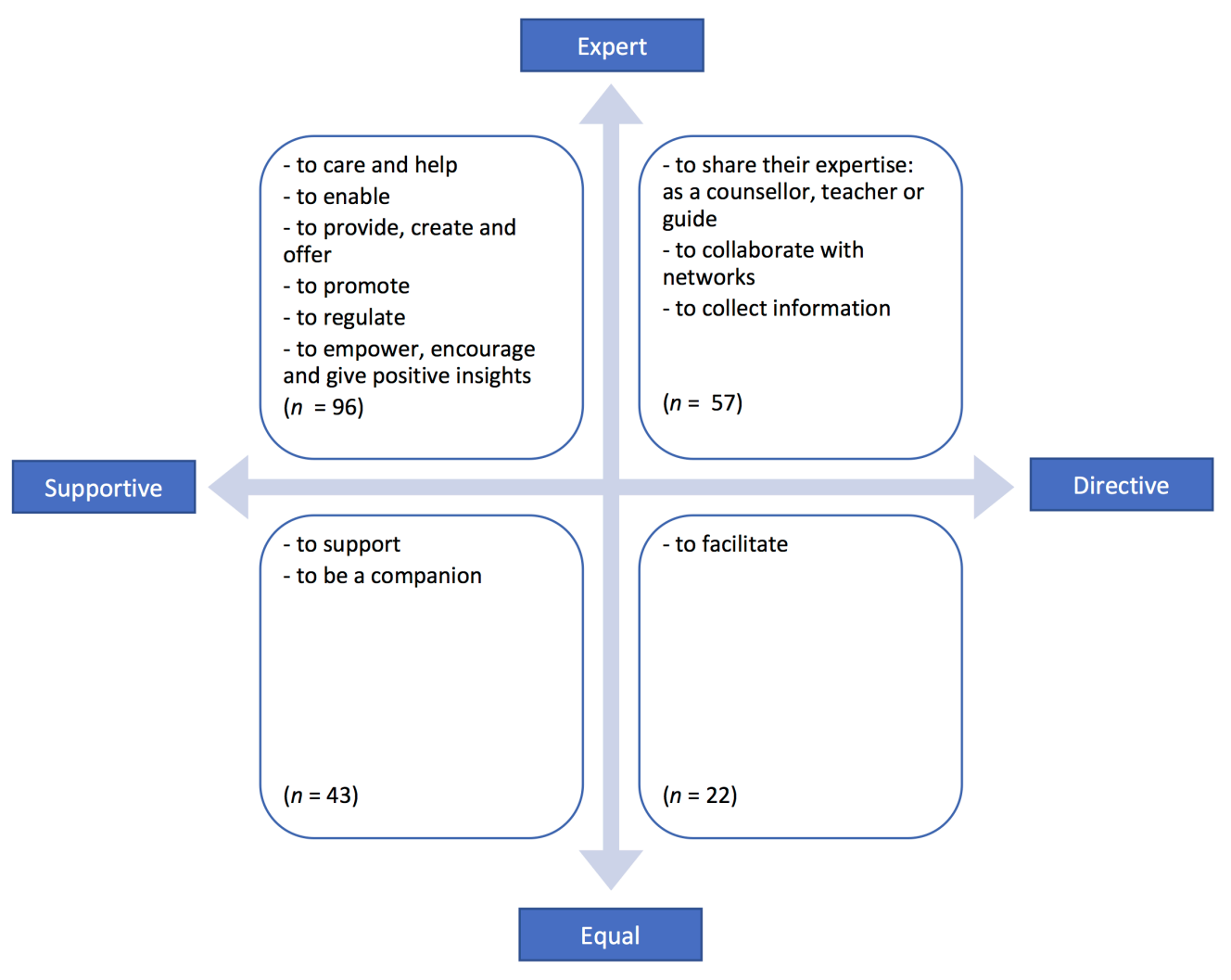

Figure 17

Mapping the role of the therapist

challenge may be reflected in the need to add new categories during the analysis of the free-text answers to the multiple choice questions.

\section{Future Guidelines}

While surveys are useful in collecting a breadth of persectives, depth is limited. For example, the results do not explain when, how and why (or why not) particular music therapy methods are used with families or how they are put into action. A follow up interview study could further explore these deeper questions.

Within the data, there are valuable suggestions for future training and education of music therapists who wish to work with families. For example, within the non-musicbased methods, verbal facilitation skills are commonly used, yet respondents see this area of practice as needing further training. These results are echoed in previous research from NICU settings (Gooding \& Trainor, 2018). While there is some music therapy literature exploring the use of verbal facilitation skills (i.e., Amir, 1999; Gooding, 2017; Lindblad, 2016; Nolan, 2005) more research is needed.

Beyond the profession of music therapy, the importance of therapists adopting mentalization approaches to increase the family's capacity for reflective functioning is highlighted in the broader research into family work across clinical populations (i.e., Dimitrova et al., 2016; Fonagy, 2012; Fossati \& Somma, 2018; Kalland et al., 2016; Pajulo et al., 2012; Philipp, 2012; Solbakken et al., 2011). The ability to mentalize is seen as a crucial part of parenting and is especially important when there are challenges in the child's development. In this survey, only one respondent mentioned including mentalization theory as part of their approach. Within the music therapy literature, mentalization is more commonly described in work with adults with mental health issues (Hannibal, 2014; Hannibal \& Schwantes, 2017; Strehlow, 2016). In the field of music therapy with families, there have only been preliminary discussions about incorporating mentalization theory as part of recent conference presentations (Lindahl-Jacobsen et al, 2018; Tuomi, 2018, 2019). It is important to acknowledge that working 
in this way requires advanced training and/or counsultation with other professionals from this field, such as family therapists. In addition, given that the broader field of family therapy includes mentalization as a key theoretical framework, there is scope for further research in this area in music therapy.

In terms of the role of the therapist in working with families, this survey only provides the therapists' perspective. Studies exploring the outcomes of family-centred sessions have demonstrated that parents and family members often gain knowledge and skills from participating in the sessions (Thompson, 2018; Schwartzberg \& Silverman, 2017; Warren \& Nugent, 2010), or from receiving parallel counselling sessions (Blauth, 2017; Gottfried, 2016). In either approach, the music therapist's facilitation style was important to the perceived success of the sessions (Edwards, 2014; Nicholson et al., 2008; Thompson, 2018). Future studies should consider researching the role of the the therapist from the family's perspective.

In addition, the survey results cannot provide a deeper insight into who is considered the "client" in family-centered music therapy sessions. In other words, is the focus on the child/adult client, on the parent/carer or on the whole family? When reflecting on the analysis to the open-text questions, it seems that the participants conceptualised their work with families as involving a child/adult client who are accompanied by others who share the session with them. This topic needs further research to better understand practice, since there are flow on ethical implications for determining the goals/focus of therapy, and for raising awareness about the potential benefits of music therapy with families. Further, more research exploring how music therapists interact with family members who are not present within the client's session, and who are not receiving parallel services, is needed.

\section{Conclusion}

Music therapy with families is well established as an important field of practice that includes a large range of populations across the life span. Music therapists working with families emphasise that the work is holistic and flexible, both in terms of the theoretical approaches that inform their work and the methods/techinques that are included in sessions. In order to ensure that this field continues to deepen and develop, music therapy training courses may need to reflect more family-centred and relational-orientated frameworks. In addition, participants in this study strongly advocated for more continuing professional development opportunities to continue to deepen their practice.

\section{About the Authors}

Kirsi Tuomi, MM, is a music-, Theraplay- and Attachment focused family therapist and certified supervisor. She has worked as a clinician over 20 years focusing on attachment issues mainly with foster and adoptive families. She regularily teaches music therapy students and has given numerous national and international presentations and workshops. Currently she is finishing her PhD studies at the University of Jyväskylä.

Grace Thompson is Head of Music Therapy at the University of Melbourne. Her research focuses on music therapy with disabled and autistic children, and delivered within ecologically oriented strategies. She is the co-editor of "Music Therapy with Families: Therapeutic Approaches and Theoretical Perspectives."

Tali Gottfried, PhD, is a licensed music therapist, certified supervisor, lecturer and researcher. Her main clinical and research areas are families of children with developmental challenges. Tali works within a parallel clinical model, where music takes a central role in the therapeutic process of both the children and their parents, MEL Assessment co-developer.

Esa Ala-Ruona, $\mathrm{PhD}$, is a music therapist and psychotherapist (advanced level) working as a senior researcher at the Music Therapy Clinic for Research and Training, at University of Jyväskylä. His research interests are in music therapy assessment and evaluation, and in studying musical interaction, meaning making and clinical process- 
es in multimodal music therapy. He has an extensive experience in clinical music therapy in various of fields of health care and rehabilitation. His special expertise lies on creating clinical models, as well as clinical practice of integrative music psychotherapy, and vibroacoustic therapy.

\section{Acknowledgements}

We want to express our warm gratitude to our colleagues who provided their expertise when formulating the survey questions on the piloting stage of the research.

\section{Appendix 1}

The questionnaire is available from the following link: https://voices.no/index.php/ voices/article/view/2952/3218

\section{Notes}

1. We have chosen to use "identity first" language in this article our of respect for disability advocacy groups who express a preference for this terminology.

2. All member numbers are from the time the survey was distributed.

\section{References}

Aasgaard, T. (2001). An ecology of love: Aspects of music therapy in the pediatric oncology environment. Journal of Palliative Care, 17(3), 177-224.

Alvin, J. (1978). Music therapy for the autistic child. Oxford University Press.

Amir, D. (1999). Musical and verbal interventions in music therapy: A qualitative study. Journal of Music Therapy, 16(2), 144-175. https://doi.org/10.1093/jmt/36.2.144

Ayson, C. (2008). Child-parent wellbeing in a paediatric ward. The role of music therapy in supporting children and their parents facing the challenge of hospitalisation. Voices: $A$ World Forum for Music Therapy, 8(1). https://doi.org/10.15845/voices.v8i1.449

Baron, A. (2017). Working with families in the acute pediatric medical setting. In S. LindahlJacobsen \& G. Thompson (Eds.), Music therapy with families. Therapeutic approaches and theoretical perspectives (pp. 45-71). Jessica Kingsley Publishers.

Beer, L. (2017). The role of the music therapist in training caregivers of people who have advanced dementia. Nordic Journal of Music Therapy, 26(2), 185-199. https://doi.org/ 10.1080/08098131.2016.1186109

Bengtsson, M. (2016). How to plan and perform a qualitative study using content analysis. NursingPlus Open, 2, 8-14. https://doi.org/. https://doi-org.ezproxy.jyu.fi/10.1016/ j.npls.2016.01.001

Blauth, L. (2016). Improving mental health in families with autistic children: Benefits of using video feedback in parent counselling sessions offered alongside music therapy. Health Psychology Report, 5(2), 138-150. https://doi.org/10.5114/hpr.2017.63558

Bronfenbrenner, U. (1979). The ecology of human development. Experiments by nature and design. Cambridge, Massachusetts, London: Harvard University Press.

Bronfenbrenner, U. (1981). Children and families: 1984. Society, 18(2), 38-41. https://doi.org/10.1007/BF02694667

Bruscia, K. (1998). Defining music therapy (2nd ed.). Barcelona Publishers.

Bruscia, K. (2016). Types of interpretivist research. In B. Wheeler \& K. Murphy (Eds.), An introduction to music therapy research (3rd ed., pp. 163-178). Barcelona Publishers.

Colegrove, V., Havighurst, S., Kehoe, C., \& Lindahl-Jacobsen, S. (2018). Pilot randomized controlled trial of Tuning Relationships with Music: Intervention for parents with a trauma history and their adolescent. Child Abuse and Neglect, 79, 259-268. https://doi.org/10.1016/ j.chiabu.2018.02.017 
Crooke, A. H. D. (2015). Music therapy, social policy and ecological models: A located example of music in Australian schools. Voices: A World Forum for Music Therapy, 15(2). https://doi.org/10.15845/voices.v15i2.829

Dimitrova, N., Turpin, H., Borghini, A., Ansermet, F., Urben, S., \& Muller-Nix, C. (2016). 6.129 lower early parental mentalization as a risk factor for child mentalization abilities in early adolescence in preterm-born children: A longitudinal study. Journal of the American Academy of Child \& Adolescent Psychiatry, 55(10), S245-S245. https://doi.org/10.1016/ j.jaac.2016.09.445

Drake, T. (2011). Becoming in tune: The use of music therapy to assist the developing bond between traumatized children and their new adoptive parents. In J. Edwards (Ed.), Music therapy and parent-infant bonding (pp. 101-114). Oxford University Press.

Edwards, J. (Ed.). (2011). Music therapy and parent-infant bonding. Oxford University Press.

Edwards, J. (2014). The role of the music therapist in promoting parent-infant attachment. Canadian Journal of Music Therapy, 20(1), 48-48. Retrieved from https://www-proquestcom.pva.uib.no/scholarly-journals/role-music-therapist-promoting-parent-infant/docview/ $1562002705 /$ se-2 ?accountid $=8579$

Edwards, J., Scahill, M., \& Phelan, H. (2007). Music therapy: Promoting healthy mother-infant relations in the vulnerable refugee and asylym seeker community. In J. Edwards (Ed.), Music: Promoting health and creating community in healthcare contexts (pp. 154-168). Cambridge Scholars Publishing.

Erlingsson, C., \& Brysiewicz, P. (2017). A hands-on guide to doing content analysis. African Journal of Emergency Medicine, 7(3), 93-99. https://doi.org/https://doi-org.ezproxy.jyu.fi/ 10.1016/j.afjem.2017.08.001

Ettenberger, M., Rojas Cárdenas, C., Parker, M., \& Odell-Miller, H. (2017). Family-centred music therapy with preterm infants and their parents in the Neonatal Intensive Care Unit (NICU) in Colombia - A mixed-methods study. Nordic Journal of Music Therapy, 26(3), 207-234. https://doi.org/10.1080/08098131.2016.1205650

Fonagy, P. (Ed.). (2012). Handbook of mentalizing in mental health practice. American Psychiatric Association Publishing.

Fossati, A., \& Somma, A. (2018). Improving family functioning to (hopefully) improve treatment efficacy of borderline personality disorder: An opportunity not to dismiss. Psychopathology, 52(2), 149-159. https://doi.org/10.1159/000486603

Gooding, L. F. (2017). Microskills training: A model for teaching verbal processing skills in music therapy. Voices: A World Forum for Music Therapy, 17(1). https://doi.org/10.15845/ voices.v17i1.894

Gooding, L., \& Trainor, B. (2018). Working with parents in the neonatal intensive care unit: An analysis of music therapy practice in the United States of America. The Arts in Psychotherapy, 59, 1-6. https://doi.org/10.1016/j.aip.2017.12.005

Gottfried, T. (2016). Creating bridges: Music-oriented counseling for parents of children with autism spectrum disorder. Aalborg Universitet. https://doi.org/10.5278/vbn.phd.hum.00042

Gottfried, T., Thompson, G., Elefant, C., \& Gold, C. (2018). Reliability of the music in everyday life (MEL) scale: A parent-report assessment for children on the autism spectrum. Journal of Music Therapy, 55(2), 133-155. https://doi.org/10.1093/jmt/thy002

Haire, N., \& MacDonald, R. (2019). Humor in music therapy: A narrative literature review. Nordic Journal of Music Therapy, 15(1), 1-18. https://doi.org/10.1080/ 08098131.2019.1577288

Hannibal, N. (2014). Implicit and explicit mentalisation in music therapy in the psychiatric treatment of people with borderline personality disorder. In J. de Backer \& J. Sutton (Eds.), The music in music therapy. Psychodynamic music therapy in Europe: Clinical, theoretical and research approaches (pp. 211-223). Jessica Kingsley Publishers.

Hannibal, N., \& Schwantes, M. (2017). Mentalization based treatment (MBT): A possible theoretical frame for music therapy practice in clinical psychiatry. Voices: A World Forum for Music Therapy, 17(2). https://doi.org/https://dx.doi.org/10.15845/voices.v17i2.897 
Haslbeck, F. (2012). Music therapy for premature infants and their parents: An integrative review. Nordic Journal of Music Therapy, 21, 203-226. https://doi.org/10.1080/ 08098131.2011 .648653

Haslbeck, F., Nöcker-Ribaupierre, M., Zimmer, M.-L., Schrage-Leitner, L., \& Lodde, V. (2018). Music therapy in neonatal care: A framework for german-speaking countries and Switzerland. Music and Medicine (Online), 10(4), 214-224. https://search-proquestcom.ezproxy.jyu.fi/docview/2157468926? accountid $=11774$

Hasler, J. (2008). A piece of the puzzle. Music therapy with looked-after teenagers and their carers. In A. Oldfield \& C. Flower (Eds.), Music therapy with children and their families (pp. 159-175). Jessica Kingsley Publishers.

Helle-Valle, A., Binder, P.-E., Anderssen, N., \& Stige, B. (2017). Is restlessness best understood as a process? Reflecting on four boys' restlessness during music therapy in kindergarten. International Journal of Qualitative Studies on Health and Well-Being, 12(1). https://doi.org/ 10.1080/17482631.2017.1298266

Hibben, J. (1992). Music therapy in the treatment of families with young children. Music Therapy, 11(1), 28-44.

Hodkinson, S., Bunt, L., \& Daykin, N. (2014). Music therapy in children's hospices: An evaluative survey of provision. The Arts in Psychotherapy, 41(5), 570-576. https://doi.org/ 10.1016/j.aip.2014.10.006

Jacobsen, S. L., \& McKinney, C. (2015). A music therapy tool for assessing parent-child interaction in cases of emotional neglect. Journal of Child \& Family Studies, 24(7), 2164-2173. https://doi.org/10.1007/s10826-014-0019-0

Jacobsen, S. L., McKinney, C., \& Holck, U. (2014). Effects of a dyadic music therapy intervention on parent-child interaction, parent stress, and parent-child relationship in families with emotionally neglected children: A randomized controlled trial. Journal of Music Therapy, 51(4), 310-332. https://doi.org/10.1093/jmt/thu028

James, R., Sigafoos, J., Green, V., Lancioni, G., O’Reilly, M., Lang, R., Davis T., Carnett, A., Achmadi, D., Gevarter, C. \& Marschik, P. (2015). Music therapy for individuals with autism spectrum disorder: A systematic review. Review Journal of Autism and Developmental Disorders, 2(1), 39-54. https://doi.org/10.1007/s40489-014-0035-4

Jordan-Kilkki, P., \& Tuomi, K. (2016). Perhekeskeinen musiikkiterapia ja dialoginen perhetyö -koulutuksen esittely [Family centered music therapy and dialogical parent couseling Introduction to the training model]. Musiikkiterapia, 31(1-2), 70-75.

Kalland, M., Fagerlund, Å., von Koskull, M., \& Pajulo, M. (2016). Families first: The development of a new menatlization-based group intervention for first-time parents to promote child development and family health. Primary Health Care Research and Development, 1(3-17). https://doi.org/10.1017/S146342361500016X

Kern, P., \& Humpal, M. (Eds.). (2012). Early childhood music therapy and autism spectrum disorders. Jessica Kingsley Publishers.

Kern, P., Rivera, N., Chandler, A., \& Humpal, M. (2013). Music therapy services for individuals with autism spectrum disorder: A survey of clinical practices and training needs. Journal of Music Therapy, 50(4), 274-303. https://doi.org/10.1093/jmt/50.4.274

Kern, P., \& Tague, D. B. (2017). Music therapy practice status and trends worldwide: An international survey study. Journal of Music Therapy, 54(3), 255-286. https://doi.org/ 10.1093/jmt/thx011

Krantz, B. (2014). Parent-infant music therapy: Effects, effectiveness and practice of music therapy for young children and their caregivers. Catholic University of Applied Sciences. https://doi.org/10.13140/RG.2.2.25500.08321

Lindahl Jacobsen, S., \& Thompson, G. (Eds.). (2017a). Music therapy with families. Therapeutic approaches and theoretical perspectives. Jessica Kingsley Publishers.

Lindahl-Jacobsen, S., \& Thompson, G. (2017b). Working with families. Emerging characteristics. In S. Lindahl-Jacobsen \& G. Thompson (Eds.), Music therapy with families. Therapeutic approaches and theoretical perspectives (pp. 309-331). Jessica Kingsley Publishers. 
Lindahl-Jacobsen, S., Gottfried, T., \& Thompson, G. (2018). Families with children with special needs: A seminar to develop music therapy practice. In 9th Nordic music therapy congress. Stockholm.

Lindblad, K. (2016). Verbal dialogue in music therapy: A hermeneutical analysis of three music therapy sessions. Voices: A World Forum for Music Therapy, 16(1). https://doi.org/ 10.15845/voices.v16i1.842.

Lindenfelser, K.J. \& Grocke, D. \& McFerran, K. (2008). Bereaved parents' experiences of music therapy with their terminally ill child. Journal of Music Therapy, 45(3), 330-348.

https://doi.org/10.1093/jmt/45.3.330

Lindenfelser, K. J., Hense, C., \& McFerran, K. (2012). Music therapy in pediatric palliative care: Family-centered care to enhance quality of life. American Journal of Hospice \& Palliative Medicine, 29(3), 219-226. https://doi.org/10.1177/1049909111429327

Loewy, J. (2015). NICU music therapy: Song of kin as critical lullaby in research and practice. Annals of the New York Academy of Sciences, 178-185. https://doi.org/10.1111/nyas.12648

Loth, H. (2008). Music therapy groups for families with a learning-disabled toddler. Bridging some gaps. In A. Oldfield \& C. Flower (Eds.), Music therapy with children and their families (pp. 53-69). London, Philadelphia: Jessica Kingsley Publishers.

McFerran, K., \& Wigram, T. (2002). A review of current practice in group music therapy improvisations. British Journal of Music Therapy, 16(1), 46-55. https://doi.org/10.1177/ 135945750201600107

Muller, P., \& Warwick, A. (1993). Autistic children and music therapy. The effects of maternal involvement in therapy. In M. Heal \& T. Wigram (Eds.), Music therapy in health and education (pp. 214-234). Jessica Kingsley Publishers.

Nicholson, J. M., Berthelsen, D., Abad, V., Williams, K., \& Bradley, J. (2008). Impact of music therapy to promote positive parenting and child development. Journal of Health and Psychology, 13(2), 226-238. https://doi.org/10.1177/1359105307086705

Nolan, P. (2005). Verbal processing within the music therapy relationship. Music Therapy Perspectives, 23, 18-28. https://doi.org/10.1093/mtp/23.1.18

O'Callaghan, C., \& Jordan, B. (2011). Music therapy supports parent-infant attachments: In families affected by life threatening cancer. In J. Edwards (Ed.), Music therapy and parentinfant bonding (pp. 191-207). Oxford University Press.

Oldfield, A. (1993). Music therapy with families. In M. Heal \& T. Wigram (Eds.), Music therapy in health and education (pp. 46-54). Jessica Kingsley Publishers.

Oldfield, A. (2008). Working in partnership and supporting parents. Music therapy for preschool children and their parents at a child development centre. In A. Oldfield \& C. Flower (Eds.), Music therapy with children and their families (pp. 19-36). Jessica Kingsley Publishers.

Oldfield, A. (2011). Parents' perceptions of being in music therapy sessions with their children: What is our role as music therapists with parents? In J. Edwards (Ed.), Music therapy and parent-infant bonding (pp. 58-72). Jessica Kingsley Publishers.

Oldfield, A. (2017). Music therapy with families in a psychiatric children's unit. In S. Lindahl Jacobsen \& G. Thompson (Eds.), Music therapy with families. Therapeutic approaches and theoretical perspectives (pp. 72-91). Jessica Kingsley Publishers.

Oscarsson, S. (2017). To create hope and dignity: Music therapy with refugee children with pervasive refusal syndrome. In S. Lindahl Jacobsen \& G. Thompson (Eds.), Music therapy with families. Therapeutic approaches and theoretical perspectives (pp. 247-268). Jessica Kingsley Publishers.

Pajulo, M., Pyykkönen, N., Kalland, M., Sinkkonen, J., Helenius, H., \& Punamäki, R.-L. (2012). Substance-abusing mother-baby-pairs in residential treatment: Importance of pre-and postnatal reflective functioning. Infant Mental Health Journal, 33(1), 70-81. https://doi.org/ 10.1002/imhj.20342

Philipp, D. A. (2012). Reflective family play: A model for whole family intervention in the infant and preschool clinical population. Infant Mental Health Journal, 33(6), 599-608.

https://doi.org/10.1002/imhj.21342 
Raglio, A., Fonte, C., Reani, P., Varalta, V., Bellandi, D., \& Smania, N. (2016). Active music therapy for persons with dementia and their family caregivers. International Journal of Geriatric Psychiatry, 31, 1084-1090. https://doi.org/10.1002/gps.4421

Ridder, H. M. (2017). Partners in care. A psychosocial approach to music therapy and dementia. In S. Lindahl Jacobsen \& G. Thompson (Eds.), Music therapy with families. Therapeutic approaches and theoretical perspectives (pp. 269-289). Jessica Kingsley Publishers.

Ridder, H. M., \& Gummesen, E. (2015). The use of extemporizing in music therapy to facilitate communication in a person with dementia: An explorative case study. Australian Journal of Music Therapy, 26, 6-29. Retrieved from https://www-proquest-com.pva.uib.no/scholarlyjournals/use-extemporizing-music-therapy-facilitate/docview/1705958547/ se-2?accountid $=8579$

Rolvsjord, R., \& Stige, B. (2015). Concepts of context in music therapy. Nordic Journal of Music Therapy, 24(1), 44-66. https://doi.org/10.1080/08098131.2013.861502

Salkeld, C. E. (2008). Music therapy after adoption. The role of family music therapy in developing secure attachment in adopted children. In A. Oldfield \& C. Flower (Eds.), Music therapy with children and their families (pp. 141-157). Jessica Kingsley Publishers.

Savage, R., \& Taylor Johnston, E. (2013). Hospice family caring behaviours during music therapy. New Zealand Journal of Music Therapy, (11), 81-103. ISSN: 1176-3264

Schwartzberg, E. T., \& Silverman, M. J. (2017). Parent perceptions of music therapy in an oncampus clinic for children with autism spectrum disorder. Musicae Scientiae, 21(1), 98-112. https://doi.org/10.1177/1029864916644420

Shoemark, H. (1996). Family-centred early intervention: music therapy in the playground program. Australian Journal of Music Therapy, 7, 3-15. ISSN: 1036-9457

Shoemark, H. (2004). Family-centered music therapy for infants with complex medical and surgical needs. In M. Nöcker-Ribaupierre (Ed.), Music therapy for premature and newborn infants (pp. 141-157). Barcelona Publishers.

Shoemark, H., \& Dearn, T. (2008). Keeping parents at the centre off family centred music therapy with hospitalised infants. Australian Journal of Music Therapy, 19, 3-24.

Shoemark, H., Hanson-Abromeit, D., \& Stewart, L. (2015). Constructing optimal experience for the hospitalized newborn through neuro-based music therapy. Frontiers in Human Neuroscience, 9, 487. https://doi.org/10.3389/fnhum.2015.00487

Smith, M., Sanderson, S., Brothers, K., Myers, M., \& McCormick, J. (2016). Conducting a large, multi-site survey about patients' views on board consent: Challenges and solutions. BMC Medical Research Methodology, 16(162). https://doi.org/10.1186/s12874-016-0263-7

Solbakken, O. A., Sandvik Hansen, R., \& Monsen, J. T. (2011). Affect integration and reflective function: clarification of central conceptual issues. Psychotherapy Research, 21(4), 482-496. https://doi.org/10.1080/10503307.2011.583696

Strehlow, G. (2016). Update mentalization in music therapy. Nordic Journal of Music Therapy, 25(Supplement 1: 10th European music therapy conference), 73. https://doi.org/10.1080/ 08098131.2016.11783620

Stuart, K. (2018). Musical ripples and reflections: The story of Charlie, his music and his new foster family. Voices: A World Forum for Music Therapy, 18(4). https://doi.org/10.15845/ voices.v18i4.2604

Teckenberg-Jansson, P., Huotilainen, M., Pölli, T., Lipsanen, J., \& Järvenpää, A.-L. (2011). Rapid effects of neonatal music therapy combined with kangoroo care on prematurely-born infants. Nordic Journal of Music Therapy, 20(1), 22-42. https://doi.org/10.1080/ 08098131003768123

Thompson, G. (2012). Family-centered music therapy in the home environment: Promoting interpersonal engagement between children with autism spectrum disorder and their parents. Music Therapy Perspectives, 30(2), 109-116. https://doi.org/10.1093/mtp/30.2.109

Thompson, G. (2017). The "Music therapy with families network": Creating a community of practice via social media. British Journal of Music Therapy, 31(1), 50-52. https://doi.org/ $10.1177 / 1359457517690070$ 
Thompson, G. (2018). Long-term perspectives of family quality of life following music therapy with young children on the autism spectrum: A phenomenological study. Journal of Music Therapy, 54(4), 432-459. https://doi.org/10.1093/jmt/thx013

Thompson, G., McFerran, K., \& Gold, C. (2014). Family-centered music therapy in the home environment: Promoting interpersonal engagement between children with autism spectrum disorder and their parents. Child: Care, Health and Development, 40(6), 840-852.

https://doi.org/10.1111/cch.12121

Tomlinson, J., Derrington, P., \& Oldfield, A. (Eds.). (2012). Music therapy in schools. Working with children of all ages in mainstream and special education. Jessica Kingsley Publishers.

Trondalen, G. (1997). Music therapy and interplay. A music therapy project with mothers and children elucidated through the concept of "appreciative recognition." Nordic Journal of Music Therapy, 6(1), 14-27. https://doi.org/10.1080/08098139709477890

Trondalen, G. (2016). Relational music therapy: An intersubjective perspective. Barcelona Publishers.

Tuomi, K. (2017). Music therapy and theraplay. Creating, repairing and strengthening the attachment bond in foster and adoptive families. In S. Lindahl Jacobsen \& G. Thompson (Eds.), Music therapy with families. Therapeutic approaches and theoretical Perspectives (pp. 173-198). Jessica Kingsley Publishers.

Tuomi, K. (2018). Nurture and play for foster families-A mentalization based group intervention. In 9th Nordic music therapy congress. Stockholm.

Tuomi, K. (2019). Nurture and play intervention for foster families-To promote well-being and reduce inequality. In 11th European music therapy conference. Aalborg.

Tuomi, K., \& Ala-Ruona, E. (2011). Music therapy for young children in Finland. Imagine Early Childhood Music Therapy Online Magazine, 2(1), 78-79.

Tuomi, K., \& Ala-Ruona, E. (2013). Varhaisiän musiikkiterapia Suomessa [Early childhood music therapy in Finland]. Musiikkiterapia, 28(1), 6-23.

Tuomi, K., Ala-Ruona, E., \& Oldfield, A. (2017). Literature review of early childhood music therapy between 1990-2012. Voices: A World Forum for Music Therapy, 17(2). https://doi.org/https://doi.org/10.15845/voices.v17i2

Walworth, D. (2012). Family-centered practice. Integrating music into home routines. In P. Kern \& M. Humpal (Eds.), Early childhood music therapy and autism spectrum disorders. Developing potential in young children and their families (pp. 233-244). Jessica Kingsley Publishers.

Warren, P., \& Nugent, N. (2010). The Music Connections Programme: Parents' perceptions of their children's involvement in music therapy. New Zealand Journal of Music Therapy, 8, 8-33. https://doi.org/1176-3264

Williams, K. E., Berthelsen, D., Nicholson, J. M., Walker, S., \& Abad, V. (2012). The effectiveness of a short-term group music therapy intervention for parents who have a child with a disability. Journal of Music Therapy, 49(1), 23-44. https://doi.org/10.1093/jmt/ 49.1.23

Williams, K., Teggelove, K., \& Day, T. (2014). Contemporary cultures of service delivery to families: Implications for music therapy. Australian Journal of Music Therapy, 25, 148-173. 